\title{
Three-Dimensional Structure of Dendritic Spines and Synapses in Rat Hippocampus (CA1) at Postnatal Day 15 and Adult Ages: Implications for the Maturation of Synaptic Physiology and Long-term Potentiation
}

\author{
Kristen M. Harris, ${ }^{1,2}$ Frances E. Jensen, ${ }^{1,2}$ and Beatrice Tsao' ${ }^{1}$ \\ 'Department of Neurology and ${ }^{2}$ The Program in Neuroscience, Children's Hospital and Harvard Medical School, Boston, \\ Massachusetts 02115
}

It has long been hypothesized that changes in dendritic spine structure may modify the physiological properties of synapses located on them. Due to their small size, large number, and highly variable shapes, standard light microscopy of Golgi impregnations and electron microscopy (EM) of single thin sections have not proved adequate to identify most spines in a sample or to quantify their structural dimensions and composition. Here we describe a new approach, the series sample, that was developed to classify by shape and subcellular composition all of the spines and synapses in a sample of neuropil by viewing them through serial EM sections. Spines in each class are then randomly selected for serial reconstruction and measurement in three dimensions. This approach was used to assess whether structural changes in hippocampal CA1 spines could contribute to the enhanced synaptic transmission and the greater endurance of long-term potentiation (LTP) that occur with maturation. Our results show a near doubling in the total density of synapses in the neuropil and along reconstructed dendrites between postnatal day 15 (PND15) and adult ages. However, this doubling does not occur uniformly across all spine and synapse morphologies. Thin spines, mushroom spines containing perforated postsynaptic densities (PSDs) and spine apparatuses, and branched spines increase by about fourfold in density between PND15 and adult ages. In contrast, stubby spines decrease by more than half and no change occurs in mushroom spines with macular PSDs or in dendritic shaft synapses. The stubby spines that remain are smaller in adults than at PND15 and the mushroom spines are larger,

\footnotetext{
Received Nov. 27, 1991; revised Feb. 7, 1992; accepted Feb. 12, 1992.

We thank Drs. John Stevens and Michael Greenberg, and ISG Technologies of Ontario, Canada, for an early, prerelease version of ICAR 80.8 , to obtain the surfaced reconstructions of Figure 10. We thank Dr. Max Snodderly for early discussions that led to the series sample idea. We also thank Greg Belmont, who helped to complete the simulations used in Figure 11, and Katrien Neukermans, Daphne Rulf, and Derek Seiburth for their insights and technical assistance. We are grateful to Linda Kirschner, Josh Simmons, Monty Brandenberg, Nariman Shambayati, and Gene Zilberstein of the Image Graphics laboratory at Children's Hospital for the reconstruction and editing software, and we thank Drs. Scott Pomeroy, Max Snodderly, John Lisman, Thomas Brown, Greg Rose, and Marian DiFiglia for their helpful comments. We also thank Dr. Nikolaus Sucher for translating Ramon y Cajal (1893) and Tanzi (1893). This work is supported by NIH-NINCDS Grant NS21184 (K.M.H.), The Alfred P. Sloan Foundation (K.M.H.), NIH-NICHD Grant HD00807 (F.E.J.), a Radcliffe Summer Project grant (B.T.), and MR Center Grant P30-HD18655 from NICHD.

Correspondence should be addressed to Kristen M. Harris, Ph.D., Department of Neurology, Children's Hospital, Enders 260, 300 Longwood $\Lambda$ venue, Boston, MA 02115.
}

Copyright (C) 1992 Society for Neuroscience $0270-6474 / 92 / 122685-21 \$ 05.00 / 0$ while no change occurs in the three-dimensional structure of thin spines. Only a few spine necks at either age are constricted or long enough to attenuate charge transfer; therefore, the doubling in synapses should mediate the enhancement of synaptic transmission that occurs with maturation. In addition, LTP is not likely to be mediated by widening of spine necks at either age. However, the constricted spine necks could serve to concentrate specific molecules at activated synapses, thereby enhancing the specificity and endurance of LTP with maturation. These results demonstrate that the new series sample method combined with three-dimensional reconstruction reveals quantitative changes in the frequency and structure of spines and synapses that are not discernable by other methods and are likely to have dramatic effects on synaptic physiology and plasticity.

Dendritic spines have been classified by their diverse shapes since their discovery at the turn of the century. From light microscopy of Golgi-impregnated neurons, Ramon y Cajal described dendritic spines as "Stacheln" and "Dornen," which refer to long spicule-like spines and shorter thorn-like spines (Ramon y Cajal, 1893, p 343). Electron microscopy (EM) revealed dendritic spines to be the major postsynaptic targets of excitatory synapses in the CNS (Gray, 1959), and fortuitous sections allowed individual spines to be identified as "stubby," "mushroom," or "thin" depending on the constriction of their necks and the size of their heads (Jones and Powell, 1969; Peters and Kaiserman-Abramhoff, 1970). Elaborately branched dendritic spines with multiple heads and synapses have been elucidated through serial EM (Hamlyn, 1962; Harris and Stevens, 1988, 1989; Chicurel and Harris, 1989; Blackstad and Kjaerheim, 1991).

Since the days of Ramon y Cajal, it has been widely believed that learning and memory may require anatomical changes in neurons (Ramon y Cajal, 1893; Tanzi, 1893; for review, see Wallace et al., 1991). Modern theoretical models have focused this interest on the geometry of dendritic spines (Diamond et al., 1970; Rall, 1970, 1974, 1977, 1978; Kawato and Tsukahara, 1983; Koch and Poggio, 1983; Wilson, 1984; Coss and Perkel, 1985; Gamble and Koch, 1987; Brown et al., 1988; Segev and Rall, 1988; Turner, 1988; Wickens, 1988; Baer and Rinzel, 1991). Depending on their exact dimensions, small changes in spine geometry (especially in the dimensions of the spine neck) could 
modulate synaptic transmission and/or the concentration of molecules in the spine head near the synapse. In addition, changes in the frequency and distribution of spines with different geometries could alter the postsynaptic integration of multiple synaptic inputs. Indeed, several results suggest that the number and structure of dendritic spines change during development, learning, memory, and long-term potentiation (LTP); furthermore, spines appear distorted in pathological conditions associated with seizures, impaired memory, and mental retardation (for review, see Scheibel and Scheibel, 1968; Purpura, 1974, 1975; Schuz, 1978; Greenough and Bailey, 1988; Harris et al., 1989; Desmond and Levy, 1990; Wallace et al., 1991).

Reconstruction from serial EM has been required to identify the shape of most spines and to measure them with sufficient accuracy to predict whether changes in their dimensions could alter their biophysical properties (Westrum and Blackstad, 1962; Spacek, 1980, 1985a,b; Stevens et al., 1980; Spacek and Hartmann, 1983; Wilson et al., 1983; Stevens and Trogadis, 1984; Andersen et al., 1987a,b; Harris and Stevens, 1987, 1988, 1989; Benshalom and White, 1988; Benshalom, 1989). Due to the labor-intensive nature of this approach, necessarily small sample sizes have been utilized. Therefore, the relative frequencies and three-dimensional structure of dendritic spines with different shapes have not been well characterized for any brain rcgion.

We have developed a new approach, the series sample method, to classify by shape, postsynaptic density (PSD) morphology, and subcellular constituents of all dendritic spines and synapses occurring in a well-specified area of the neuropil. In the most general application of the series sample method, every structure transected by a reference section, that is, a single section in the middle of a series, is viewed through adjacent serial sections to obtain an unambiguous identification. The frequencies of the different structures are then computed per unit area of neuropil and adjusted to account for differences in the probability of viewing them on the reference section, based on the number of serial sections they traverse. Even this simple classification can be time consuming. To minimize the number of samples required to achieve robust findings, variability from sample to sample is reduced by subtracting from the sample areas the sectioned areas of structures that occur nonuniformly across the neuropil. Once all of the structures in a series sample are classified, subpopulations of structures with specific characteristics are randomly selected for complete reconstruction and measurement in three dimensions.

In the present study, this strategy was used to answer three questions. First, do the densities of different types of dendritic spines and synapses occurring in a random sample of neuropil reflect their distribution along individual dendrites coursing through the neuropil? Second, do spine dimensions occur along a continuum, thereby suggesting differentiation and remodeling between shapes, or are the dimensions and characteristics of spines in different shape classes sufficiently distinct to suggest different functions for the different classes? Third, are the necks of spines in any category constricted or long enough to reduce charge transfer from the synapse to the parent dendrite, thereby providing an anatomical basis for modulating synaptic transmission? In addition, we quantified the complete three-dimensional structure of spines of all shapes and present the detailed dimensions for testing in other models of the biophysical properties of dendritic spines.

We utilized the series sample method and three-dimensional reconstructions in rat hippocampal area CA1 at postnatal day
(PND15) and adult ages to identify changes in spine and synaptic structure that could contribute to the maturation of synaptic physiology and LTP. Specifically, earlier studies have shown that excitatory transmission is more effective at adult than at PND15 hippocampal synapses (e.g., Purpura et al., 1968; Schwartzkroin and Altschuler, 1977; Schwartzkroin, 1982; Harris and Teyler, 1983, 1984; Michelson and Lothman, 1989). LTP is an enduring enhancement of synaptic transmission that results from appropriate stimulation of presynaptic axons and is considered to be a good candidate for a cellular mechanism of learning and memory (Baudry and Davis, 1991). During development, LTP is first enduring (beyond $2 \mathrm{hr}$ posttetanus) at PND15; however, for up to $4 \mathrm{hr}$ posttetanus the magnitude of potentiation can be high before declining to a lower stable level or to the pretetanus baseline (Baudry et al., 1981; Harris and Teyler, 1984; Muller et al., 1989; Jackson et al., 1991). This pattern contrasts with adults, where the lower stable potentia tion is reached within 30 min posttetanus (Harris and Teyler, 1984; Malenka, 1991). Furthermore, quantal analyses suggest that presynaptic mechanisms may serve to maintain LTP in the immature hippocampus (Bekkers and Stevens, 1990; Malinow and I'sien, 1990), while postsynaptic mechanisms may predominate in the mature hippocampus (Friedlander et al., 1990; Fostcr and McNaughton, 1991; McNaughton, 1991). If synaptic physiology is influenced by dendritic spine morphology, then age-related differences in their structure should be compatible with the enhanced synaptic transmission and stability of LTP in adults, and with the early high magnitude of potentiation and the variability in the endurance of LTP at PND15 and younger ages.

\section{Materials and Methods}

\section{Tissue preparation}

Two male rats of the Long-Evans strain aged between postnatal days 14 and 15 (referred to as PND15) and two that were approximately 40 and $70 \mathrm{~d}$ old (young adults, referred to as adult) were prepared for serial electron microscopy (EM) (the adults were from Harris and Stevens, 1989). Intracardiac perfusion was performed under deep pentobarbital anesthesia with fixative containing $2 \%$ paraformaldehyde, $2.5 \%$ glutaraldehyde, and $2 \mathrm{mM} \mathrm{CaCl}_{2}$ in $0.1 \mathrm{M}$ cacodylate buffer at $\mathrm{pH} 7.35,37^{\circ} \mathrm{C}$, and 4 psi backing pressure from compressed gas $\left(95 \% \mathrm{O}_{2}\right.$ and $\left.5 \% \mathrm{CO}_{2}\right)$. After $1 \mathrm{hr}$, the hippocampi were dissected and then sliced at $400 \mu \mathrm{m}$ thickness perpendicular to the long axis. These slices were washed with slow continuous agitation in five changes of buffer over 30-45 min, soaked for $1 \mathrm{hr}$ in $1 \% \mathrm{OsO}_{4}$ with $1.5 \% \mathrm{~K}_{4} \mathrm{Fe}(\mathrm{CN})_{6}$ mixed just prior to immersion and for $1 \mathrm{hr}$ in $1 \% \mathrm{OsO}_{4}$, and then rinsed five times over $30 \mathrm{~min}$ in $0.1 \mathrm{M}$ cacodylate buffer and two quick changes of distilled water. The slices were dehydrated at room temperature through graded cthanols to $100 \%$ (4 changes) for $10 \mathrm{~min}$ each, including $1 \%$ uranyl acetate in $70 \%$ ethanol for $1 \mathrm{hr}$, followed by propylene oxide, and embedded in Epon (Epon : propylene oxide overnight and then fresh Epon at $60^{\circ} \mathrm{C}$ for $\left.48 \mathrm{hr}\right)$. Warm Epon blocks $\left(60^{\circ} \mathrm{C}\right)$ were hand trimmed, followed by precision glass trimming at room temperature on a Reichert Ultracut III ultramicrotome to a trapezoid containing the CAl pyramidal cell bodies and the entire apical dendritic arbor (Fig. 1 $a$ ). Five sets of serial sections, one from each of the PND15 animals, one from the first adult animal, and two sets from the second adult animal, were mounted on Formvar-coated slot grids (Synaptek, Pella), and stained for 5 min with Reynolds' lead citrate. Each grid of each series was mounted in a grid cassette (Stevens and Trogadis, 1984, or part number SRH-10Mod for JEOL side entry electron microscopes) and stored in a numbered gelatin capsule.

\section{Series sample method}

Electron microscopy and sample field selection. The grid cassettes were mounted on a rotating stage for photography at a JEOL 100B (at 6600 $\times$ ) or $1200 \mathrm{EX}$ (at $4000 \times$ ) electron microscope. The grids were rotated to 
Table 1. Summary of corrections for inhomogeneity among the series sample areas to obtain the HN areas

\begin{tabular}{lcc} 
Measure & PND15 & Adult \\
\hline Areas of all dendrites & & \\
$\quad$ Mean & 1.3 & 1.3 \\
Variance & 2.3 & 4.3 \\
$n$ & 201 & 189 \\
Areas of remaining dendrites & & \\
$\quad$ Mean & 0.40 & 0.45 \\
Variance & 0.06 & 0.05 \\
$n$ & 117 & 131 \\
Total sample area & 877 & 1044 \\
Excluded dendrite area & 218 & 180 \\
Excluded other area & 0 & 29 \\
Homogeneous neuropil & 659 & 835 \\
\% DA/SA (mean \pm SD) & $30 \pm 9$ & $23 \pm 3$ \\
\% DA/HN (mean \pm SD) & $7 \pm 2$ & $7 \pm 2$
\end{tabular}

All areas are in $\mu \mathrm{m}^{2} ; n=$ the number of dendrites. Other excluded areas included myelinated axons and portions of cell bodies. $\mathrm{DA}=$ dendritic cytoplasm areas, $\mathrm{SA}=$ sample area, $\mathrm{HN}=$ homogeneous neuropil. (To obtain a minimum of 100 $\mu \mathrm{m}^{2}$ of $\mathrm{HN}$ area with less work in the future, the initial sample areas could be reduced to $175 \mu \mathrm{m}^{2}$ and still achieve $103 \mu \mathrm{m}^{2}$ of $\mathrm{HN}$ even in the case that had the greatest amount of dendritic cytoplasm, i.e., $41 \%$ of the sample area.)

position the top and bottom edges of the sections parallel to the calibrated photographic screen, and then moved perpendicularly from the cell body layer the number of screens needed to reach $200-250 \mu \mathrm{m}$ from the pyramidal cell bodies (Fig. $1 b$ ). At this location, a strip across stratum radiatum, measuring about $25 \mu \mathrm{m}$ wide and running parallel to the pyramidal cell bodies, was divided into $8-10$ equal fields, and a random number table was consulted to determine which of these fields to photograph through adjacent serial sections (Fig. 1c).

For the PND15 animals, 35-39 serial sections were photographed, and for the adult animals, 27-68 serial sections were photographed. A calibration grid was photographed with each series, and all prints of the series were viewed with an illuminated magnifying ring. The middle reference section contained the sample field of $200 \mu \mathrm{m}^{2}$ located in the center of the $500 \mu \mathrm{m}^{2}$ photographic field.

Section thickness. The diameters of the longitudinally sectioned mitochondria, which are cylindrical, were measured at their maxima in single sections. Then, the number of sections in which the mitochondria appeared was counted (IIarris and Stevens, 1987, 1988, 1989). Section thickness was then estimated: thickness $(\mu \mathrm{m} / \mathrm{section})=$ measured diameter $(\mu \mathrm{m}) \div$ number of sections. Six to twenty mitochondria per series were measured by this formula, and the average section thickness for a series ranged from 0.055 to $0.110 \mu \mathrm{m}$.

Sample field and homogeneous neuropil areas. At the electron microscope, the photographic fields were positioned to exclude cell bodies and blood vessels that randomly fell within the sample area. The areas of portions of cell bodies and myelinated axons that were not recognized at the EM, and therefore not excluded from the photographic field, were traced and subtracted from the total sample area. Dendritic processes were not uniformly sectioned, and therefore they produced large variability in the density of synapses in the neuropil (Fig. 2). To reduce this variability, each process in the neuropil was identified as dendritic or otherwise by viewing it through serial sections, and the area of sectioned dendritic profiles was measured on the reference section. The dendritic process areas were then excluded until all sample fields had a normal distribution and homogeneity of variance in the remaining dendritic process areas. For these sample fields, homogeneity in the variance was achieved by excluding all dendritic processes with areas greater than $0.94 \mu \mathrm{m}^{2}$ on the reference section. The homogeneous neuropil area (HN) calculated for each photographic series was

$\mathrm{HN}=$ sample area - (area of glia + myelinated axons + cell bodies $)$ - area of excluded dendritic cytoplasm.

This adjustment resulted in a decrease in the area of the sample field occupied by dendritic cytoplasm from $30 \%$ to $7 \%$ at PND15 and from $23 \%$ to $7 \%$ in the adult (Table 1 ).

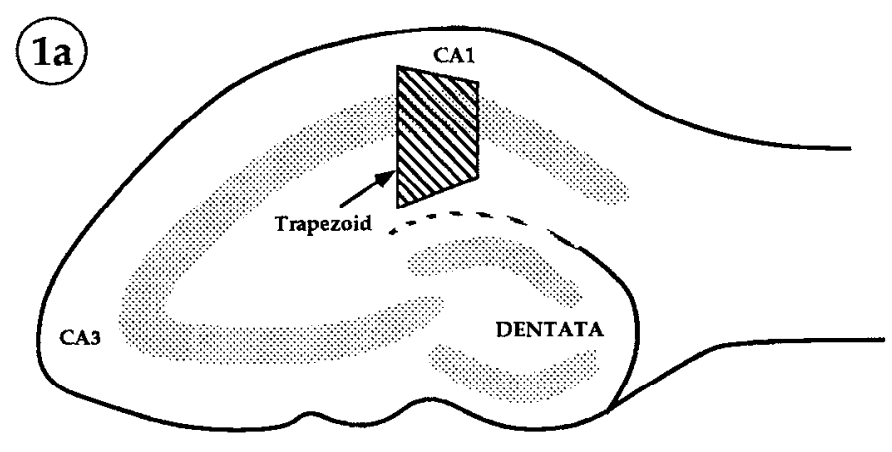

(1b)

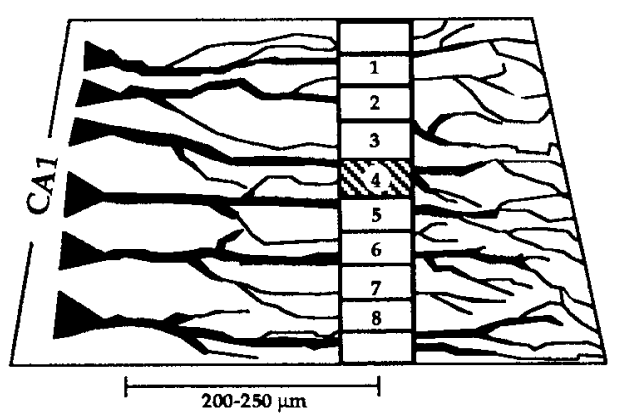

(1c)

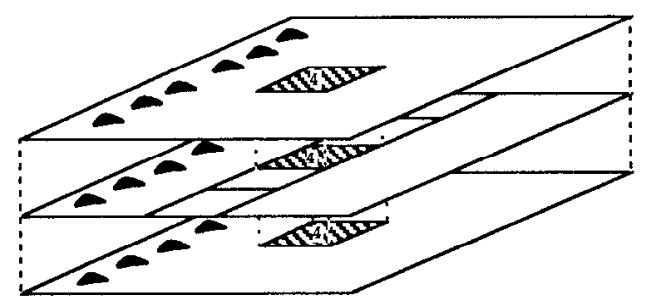

Figure 1. Procedure to locate and to select randomly the sample fields in stratum radiatum of hippocampal area CA1. $a$, Trapezoids were positioned to contain the pyramidal cell bodies and all of the apical dendritic arbor. $b$, Then, the distance from the pyramidal cells to the sample area was measured with the calibrated photographic screen at the electron microscope. A strip across stratum radiatum at 200-250 $\mu \mathrm{m}$ from the pyramidal cells was divided equally into a set of $500 \mu \mathrm{m}^{2}$ fields. The two unnumbered fields at the edges of the section were excluded because some sections in the series had compression at the edges or were slightly ragged. $c$, A random number table was consulted to ascertain which field(s), for example, field 4, to photograph through serial thin sections.

Characteristics of dendrites in the series samples. Longitudinally sectioned (LONG) dendrites were characterized by long segments of microtubules and long cylindrical mitochondria; cross-sectioned $(\mathrm{X})$ dendrites had cross-sectioned microtubules and circular mitochondria; and obliquely sectioned (OB) dendrites contained short lengths of microtubules, and oval mitochondria. "Spiny" dendrites had at least one dendritic spine, and "nonspiny" dendrites had no spines but at least one dendritic shaft synapse. The diameters of all dendrites in each series sample were measured, perpendicularly to their microtubules, on the reference section.

Criteria for including synapses in the series samples. All axonal varicosities and dendrites in the sample fields were systematically searched on both the reference section and the adjacent sections for the presence of a PSD. Synapses with cross-, obliquely, or tangentially sectioned PSDs were included if the PSD and cleft material were present on the reference section, and synaptic vesicles were present on the reference section or an immediately adjacent section. In this way, synapses cut at all angles, and the edges of synapses, were unambiguously identified through serial sections and included in the sample. PSDs touching the edges of the sample field lines were included in the sample and accounted for one to three synapses per sample field at both PND15 and adult ages.

Correction for differences in the probability of viewing PSDs on the 

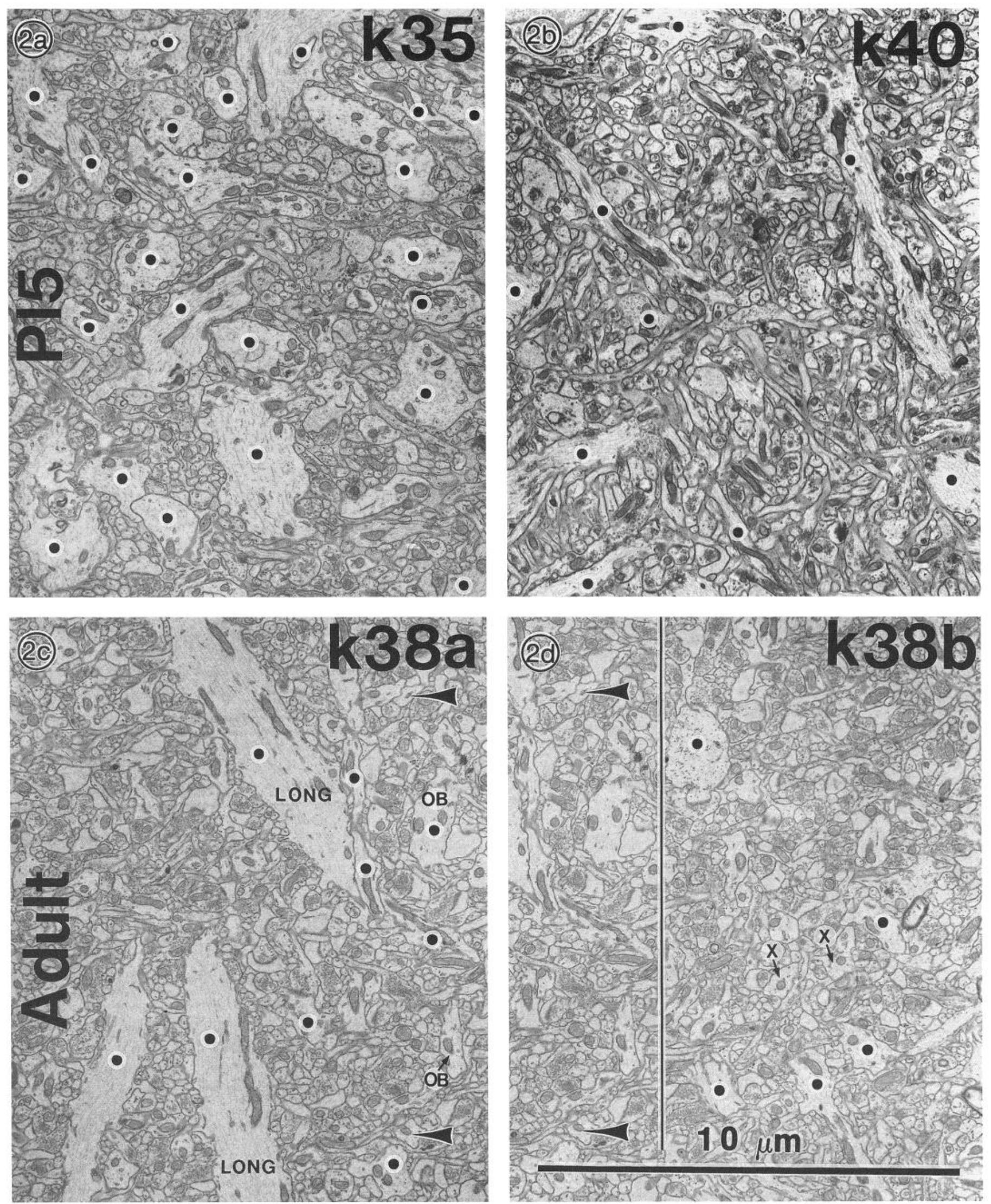

Figure 2. Neuropil on the reference section of series samples from PND15 and adult ages. One sample field from PND15 ( $a$, series number $k 35$ ) has several dendrites with areas $>0.94 \mu \mathrm{m}^{2}$ (labeled with large dots) while another sample field from PND15 $(b$, series number $k 40)$ has few dendrites with areas $>0.94 \mu \mathrm{m}^{2}$. Much of the sample area in the left half of adult series number $\mathrm{k} 38(c, k 38 a)$ contained large dendritic cytoplasm, while the neighboring neuropil $(d, k 38 b)$ had few large dendrites. Arrowheads in $c$ and $d$ are pointing to the same structures in the overlapping 
reference sections of the series samples. Since PSDs have different sizes, shapes, or orientations relative to the plane of section, the probability of viewing them on the reference section differs proportionally to the number of sections they occupy (Braendgaard and Gundersen, 1986; Harris et al., 1989). To take this into account, the number of serial sections in which each PSD appeared was counted, and then when grouping the synapses by spine shape, PSD morphology, or type of dendritic shaft, the number of sections for the PSDs in each category was averaged. The following formulas were then used to adjust the relative synaptic densities to account for significant differences in the probability of viewing them on the reference section either between ages or within an age when comparing the different spine and synapse types:

$$
\begin{aligned}
& \mathrm{USD}=(\# \text { synapses } / \mathrm{HN}) * 100, \\
& \mathrm{ASD}=\mathrm{USD} *\left(s^{\prime} / s\right),
\end{aligned}
$$

where USD is the unadjusted synaptic density (\# synapses $/ 100 \mu \mathrm{m}^{2}$ ) in the homogeneous neuropil (HN), ASD is the adjusted synaptic density in the homogeneous neuropil, $s^{\prime}$ is the mean number of sections in the category or age with the fewest sections, and $s$ is the mean number of sections in the other categories or age groups with more sections.

\section{Three-dimensional reconstructions}

Frequency of synapses and dendritic spines along reconstructed spiny dendritic segments in the series samples. Three spiny dendritic segments were randomly selected from the sample population of cross- or obliquely sectioned dendrites on each reference section, for a total of 12 dendrites from the PND15 and 15 dendrites from the adult series samples. Only the cross- or obliquely sectioned dendrites were reconstructed because the spine origins leaving the tangentially cut walls of the longitudinally sectioned dendrites often could not be traced to completion in these relatively short series. The reconstructions were obtained by positioning the EM photomicrographs under a video camera, capturing the image in a Gould frame grabber that was interfaced to a VAX 11/ 780 , and using AUTOTRACE software developed at Children's Hospital Image Graphics Laboratory to trace outlines of the plasmalemma. The images of adjacent sections were microaligned by switching between the stored image and the live image (Stevens et al., 1980; Stevens and Trogadis, 1984; Harris and Stevens, 1988, 1989). The data from these reconstructions were subsequently analyzed and edited using the PANDORA programs (Pearlstein et al., 1986). Every spine and synapse originating from a reconstructed dendrite was viewed through serial sections to determine its shape category, and their relative frequencies were computed per micron length of reconstructed dendrite.

Computation of postsynaptic density areas (PSD areas). The total area of every PSD on the reference section was measured through serial reconstruction. For cross-sectioned synapses, the area of the PSD equalled its length on adjacent sections multiplied by section thickness and added across sections. For obliquely or tangentially sectioned PSDs, the enclosed areas were measured and if more than one adjacent sections contained portions of the PSD, a connector was drawn where the areas overlapped and the total area equalled the enclosed areas plus the length of each connector multiplied by the section thickness.

Three-dimensional reconstruction and measurement of dendritic spines in each shape class. Six dendritic spines, two in each shape class, were randomly selected from each sample field at PND15 and adult ages and reconstructed in three dimensions using the AUTOTRACE and PANDORA software. Spines were removed at their origins from the dendrites and then edited into head and neck compartments with the PANDORA editing facility. Spine head and neck volumes, diameters, and PSD areas were computed as described in Harris and Stevens (1988, 1989). For longitudinally sectioned spines the lengths were obtained, where possible, within a single section. For obliquely or cross-sectioned spines, the lengths of the spine neck, head, and shortest length from the spine origin to the PSD were obtained by connecting a line through the center of each section and computing by the Pythagorean theorem:

$$
\text { total length }=\sum_{i=1}^{n} \sqrt{\left(t^{2}+l^{2}\right)}
$$

where $t$ is the section thickness, $l$ is the length of a line positioned from the center of a portion of the dendritic spine on one section inserted to account for displacement on the adjacent section, and $n$ is the number of sections traversed. In addition, quantitative data obtained in the three-dimensional reconstructions from Harris and Stevens (1989) and from a nonrandom selection of dendritic spines ( $K$. Neukermans and K. M. Harris, unpublished observations) were included in Table 5 to present the full range in spine dimensions that we have measured to date. All of these reconstructions were obtained from a subset of the same serial sections from which the random selections were obtained.

\section{Biophysical modeling}

Software supplied by Dr. Charles Wilson (Department of Anatomy, University of Tennessee, Heath Science Center, Memphis, TN) was used to test whether it is likely that the necks of the reconstructed spines are sufficiently long or thin to reduce charge transfer to the recipient dendrite (Wilson, 1984; Harris and Stevens, 1988, 1989). For all of the simulations, the membrane resistivity $\left(R_{m}\right)$ was set to $2000 \Omega \cdot \mathrm{cm}^{2}$, the internal cytoplasmic resistivity $\left(R_{i}\right)$ was set to $100 \Omega \cdot \mathrm{cm}$, and alpha was set at 50 to simulate the shape of a transient EPSP. Wilson found that the critical geometrical factors affecting charge transfer are the diameter and length of the spine neck constriction, which cause an increase in axial resistance as the spines become longer and thinner. Dendritic diameters greater than $0.5 \mu \mathrm{m}$ and spine head diameters less than 1.5 $\mu \mathrm{m}$ have no appreciable effect on charge transfer in the simulation and were set at 0.75 and $1.5 \mu \mathrm{m}$, respectively, as in Wilson (1984). The critical biophysical parameter is the synaptic conductance $\left(G_{\max }\right)$, where the attenuating effect of a particular spine neck constriction is greater with larger $G_{\max }$ values. Hence, the simulations were run repeatedly for neck diameters ranging from 0.01 to $0.5 \mu \mathrm{m}$, neck lengths ranging from 0.2 to $3 \mu \mathrm{m}$, and $G_{\max }$ values ranging from 0.5 to $6 \mathrm{nS}$ to cover the ranges of measured neck dimensions and a broad range in synaptic conductances.

\section{Statistical analyses}

The RS1 statistical package (Bolt, Beranek, and Newman, Cambridge, MA) was used to obtain means, standard deviations, standard errors of the mean, ranges, correlations, and statistical tests for significant differences described in the Results. For comparisons between or within ages, the sample distributions were first tested for normality by the Wilkes-Shapiro test, and by the $F$ test for homogeneity of variance. If the distributions were normal, then a parametric $t$ test for equal or nonequal variances was applied to test differences between mean values. The nonparametric Mann-Whitney $U$ statistic for medians was used for comparisons if the distributions were not normal, and the $\chi^{2}$ test was used to compare categorical data.

\section{Results}

Characteristics of dendrites, spines, and synapses in the series samples

At both ages, the thick apical dendrites of the CA1 pyramidal cells tended to be longitudinally sectioned (LONG, Fig. $2 c$ ) and the thinner lateral dendritic branches tended to be cross-sectioned (X, Fig. $2 d)$ or obliquely sectioned (OB, Fig. $2 c, d)$. The diameters of the spiny, but not the nonspiny, dendrites decreased significantly between ages PND15 and adult (Table 2). These spiny and nonspiny dendrites were the origins of all the shaft synapses and $85 \%$ of the PND15 and $76 \%$ of the adult spine synapses on the reference sections and described in the series samples below. All other spine origins occurred on dendrites not transected by the reference section.

portions of the $\mathrm{k} 38$ sample field, and the vertical line delineates the beginning of the ncighboring field in $\mathrm{k} 38 \mathrm{~b}$. A few dendrites are labeled in $c$ and $d$ for their section angles as described in Materials and Methods: $L O N G$, longitudinally, $X$, cross-, and $O B$, obliquely sectioned dendrites. Only half of each sample field is presented here due to publication size limitations. Scale bar d is for $a-d$. 


\section{(3)}

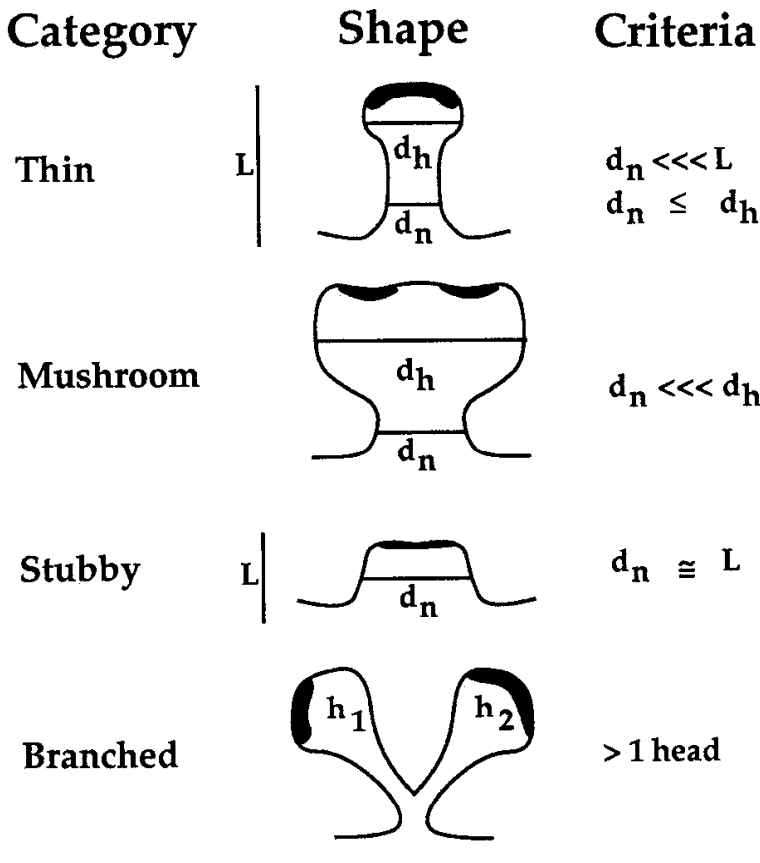

Figure 3. Criteria for assigning dendritic spines to one of four shape classes. Spines were judged thin if serial viewing revealed the length to be greater than the neck diameter, and the diameters of the head and neck to be similar. Spines were judged mushroom if the diameter of the head was much greater than the diameter of the neck. Spines were judged stubby if the diameter of the neck was similar to the total length of the spinc, and branched spincs had more than one head. Occasionally, spines in the mushroom category overlapped the thin and stubby shape categories, especially at PND15. This nomenclature follows that of Peters and Kaiserman-Abramhof (1970); similar spine shapes were described by Jones and Powell (1969) as "sessile" for the stubby spines and "pedunculated" for the mushroom or thin spines in neocortex. $L$, length; $d_{n}$, diameter of the spine neck; $d_{h}$, diameter of the spine head; $h=$ head.

Using the qualitative criteria of Figure 3, all dendritic spines were classified into the four shape categories of thin, mushroom, stubby, or branched by viewing them across serial thin sections. Single sections of a few longitudinally sectioned dendritic spines were representative of their three-dimensional structure (Fig. 4). All dendritic spines had asymmetric synapses (Gray's type I) characterized by a thickened PSD on the spine head adjacent to a widened cleft with dense staining material and a presynaptic axonal varicosity containing round clear vesicles. These are likely to be excitatory (Gray, 1959; Andersen, 1987). PSDs were classified as macular if the thickening was continuous when viewed through serial sections (Fig. $4 a-c, e-i$ ), and perforated if the PSD was interrupted by electron-lucent regions (Fig. $4 d$ ). The presence or absence of a spine apparatus was also noted for all dendritic spines in the sample fields. In the adults, the spine apparatuses were characterized by two or more flattened tubes of smooth endoplasmic reticulum (SER) surrounding bands of dense-staining material (Fig. 4d). At PND15, structures referred to as pre-spine apparatuses were observed to have beaded strings of SER dangling from flattened SER (Fig. 4c), or tubes of SER
Table 2. Diameters (in $\mu \mathrm{m}$ ) of dendrites occurring in the sample fields on the reference sections

\begin{tabular}{llll} 
Type of dendrite & $\begin{array}{l}\text { PND15 } \\
(\text { mean } \pm \text { SEM) }\end{array}$ & $\begin{array}{l}\text { Adult } \\
(\text { mean } \pm \text { SEM) }\end{array}$ \\
\hline LONG spiny & $1.11 \pm 0.09$ & $0.95 \pm 0.06$ & $<0.05$ \\
X/OB spiny & $0.79 \pm 0.11$ & $0.63 \pm 0.03$ & $<0.0001$ \\
LONG nonspiny & $0.93 \pm 0.11$ & $1.37 \pm 0.25$ & NS \\
X/OB nonspiny & $0.87 \pm 0.07$ & $0.94(n=1)$ & NS
\end{tabular}

LONG = longitudinally sectioned dendrites; $\mathrm{X} / \mathrm{OB}$, combined values of crossand obliquely sectioned dendrites that did not differ significantly from one another at either age. The diameter of each dendrite was measured on the serial section that had the maximal central diameter in the plane of section. The mean LONG diameters are underestimated because a chord is measured instead of the true diameter when these are sectioned near to their tangential edge on the reference section. The diameters of five randomly selected LONG dendrites were measured through serial sections at a designated location to obtain an average underestimate of $15 \%$ for the LONG dendrites. A process without spines or shaft synapses was classified as nondendritic. In the PND15 sample fields, 318 processes, and in the adult sample fields, 220 processes, were indistinguishable from small dendrites on the reference section, but when viewed across serial sections they were identified as axons, glia, or still not identifiable. NS, no significant differences between PND15 and adults.

that were clustered adjacent to the PSDs (Fig. 4e). Dendritic shaft synapses were either asymmetric (Fig. $4 g, h$ ), or symmetric (Gray's type II, e.g., Fig. 4i). The symmetric synapses were characterized by slightly thickened pre- and postsynaptic membranes at the cleft, and by the presence of smaller round and flattened vesicles. These are likely to be inhibitory synapses (Andersen, 1987).

\section{Densities of different synaptic and dendritic spine morphologies}

Series samples. PND15 and adult synapses were viewed and classified through serial sections; their density was expressed as the number per $100 \mu \mathrm{m}^{2}$ of $\mathrm{HN}$ and then corrected for differences in the probability of viewing them on the reference section based on the number of sections they traversed (Fig. $5 a$ ). The total density of synapses nearly doubled from $28 \pm 4$ synapses/ 100 $\mu \mathrm{m}^{2}$ of $\mathrm{HN}$ at PND15 to $55 \pm 8$ synapses $/ 100 \mu \mathrm{m}^{2}$ of HN in adults. The density of synapses in the neuropil increased by about fourfold between PND15 and adults for the thin spines $(p<0.002)$, the mushroom spines with perforated PSDs $(p<$ $0.001)$, and the branched spines $(p<0.05)$. The density of synapses decreased by more than half between PND 15 and adults for the stubby spines $(p=0.05)$, and there were no significant differences between PND15 and adults in the density of mushroom spines with macular synapses or in the density of asymmetric and symmetric dendritic shaft synapses. Symmetric synapses occurred on the necks of only two adult mushroom spines.

Reconstructed dendritic segments in the series samples. The 12 reconstructed dendritic segments from age PND15 ranged in length from 2.94 to $5.28 \mu \mathrm{m}$ (mean, $3.86 \mu \mathrm{m}$ ) and ranged in diameter from 0.39 to $1.30 \mu \mathrm{m}$ (mean, $0.75 \mu \mathrm{m}$ ). The $15 \mathrm{re}-$ constructed dendritic segments from the adults ranged in length

Figure 4. Longitudinally sectioned dendritic spine and shaft synapses in stratum radiatum of hippocampal area CA1 located approximately 250 $\mu \mathrm{m}$ from the pyramidal cell body layer. $a$ and $b$, PND15 and adult thin dendritic spines. $c$ and $d$, PND15 and adult mushroom dendritic spines. $e$ and $f$, PND 15 and adult stubby dendritic spines. $g$ and $h$, PND15 and adult asymmetric dendritic shaft synapses. $i$, Adult symmetric dendritic shaft synapse at the open arrow. Open arrows, PSDs; ser, smooth endoplasmic reticulum; $b d$, beaded SER; sa, spine apparatus; $p f$, perforation in the PSD. Scale bar in $f$ is for $a-i$. 

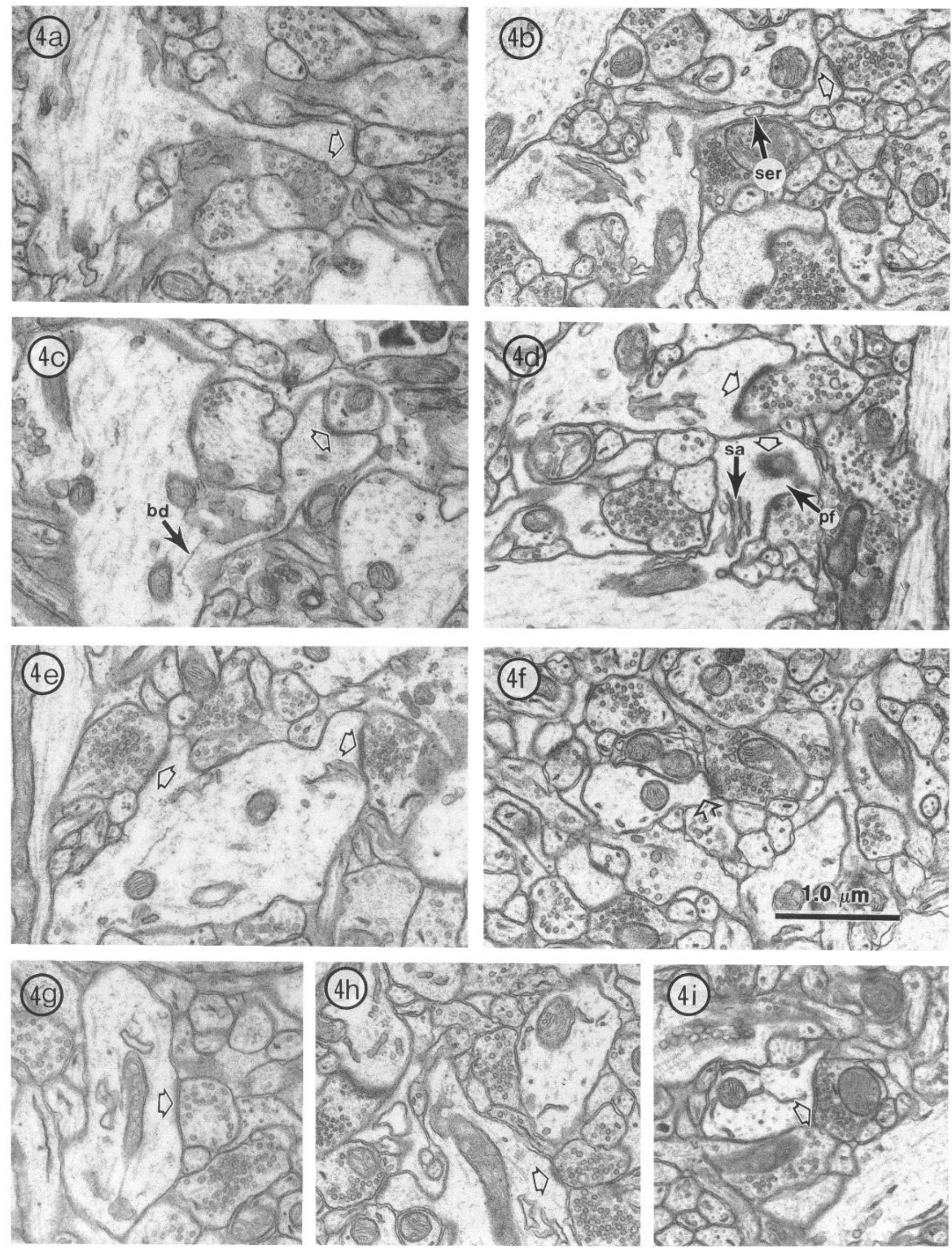
Figure 5. Frequency of synapses on different types of postsynaptic elements. $a$, Series sample. The synaptic densities are plotted per $100 \mu \mathrm{m}^{2}$ of HN for each synaptic and spine type. The adjustment for $\mathrm{HN}$ decreased the relative variability $(\mathrm{SD} /$ mean $* 100 \%)$ in synaptic density across sample fields from $23 \%$ to $12 \%$ at PND15 and from $16 \%$ to $14 \%$ in the adults. PSDs on thin spines had $16 \%$ more sections $(p<$ 0.01 ), the mushroom spines with perforated PSDs had 34\% more sections $(p<0.001)$, and the mushroom spines with macular PSDs had 24\% more sections $(p<0.0001)$ in the adult than in the PND15 samples; these percentages were used to adjust down the adult values. At PND15, four dendritic spines were incomplete within their series, and three of these were too incomplete to classify by shape. In the adults, 40 dendritic spines were incomplete but only one was too incomplete to classify by shape. $b$, Three-dimensional reconstructions of randomly selected dendrites in the series sample. The frequency of synapses along reconstructed dendritic segments that coursed throughout the same sample ficlds also doubled between PND15 and adults, and the relative distributions of spines in each shape category were similar to the overall series sample. $s d$, standard deviation.
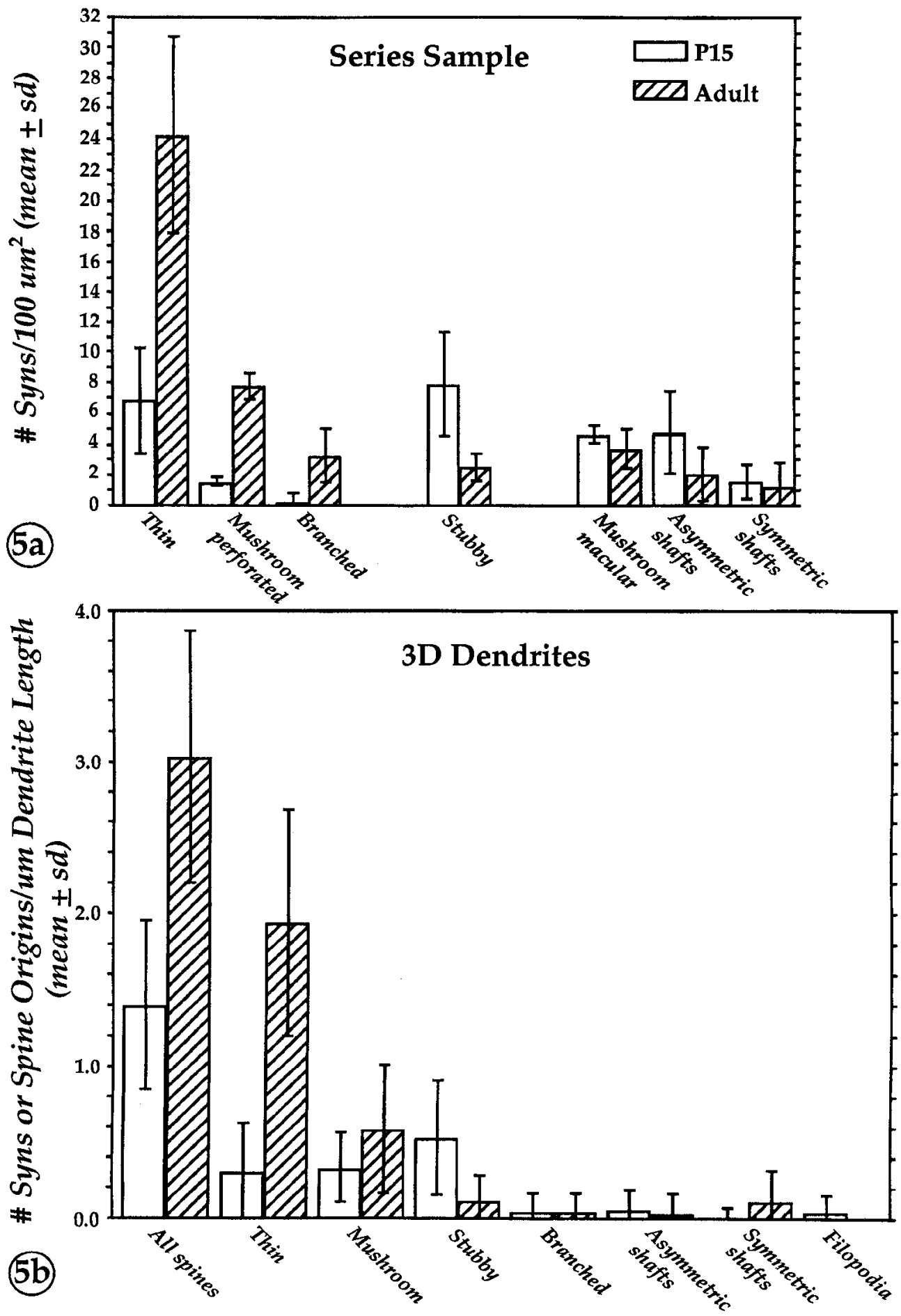

from 1.82 to $6.84 \mu \mathrm{m}$ (mean, $3.80 \mu \mathrm{m}$ ) and ranged in diameter from 0.41 to $0.82 \mu \mathrm{m}$ (mean, $0.59 \mu \mathrm{m}$ ). Like the series sample, the number of synapses along the reconstructed dendritic segments doubled between PND15 and adults; nearly quadrupled for the thin spines $(p<0.0001)$; doubled over all mushroom spines, which were not separated by PSD shape for these samples $(p<0.05)$; and halved for the stubby dendritic spines $(p<0.01)$ (Fig. $5 b$ ). Too few branched spines and asymmetric shaft synapses were observed along the reconstructed dendrites to test for differences between PND1 5 and adults, and there was a small but significant increase in the number of symmetric shaft syn- apses $(p<0.01)$. Filopodia, long protrusions from the dendrites, occurred along the reconstructed dendritic segments at PND15. Filopodia were not counted in the series sample because they had no synapses anywhere along their lengths. A direct comparison between the series samples and the reconstructed dendrites, of the proportions of spines and synapses in the different categories, revealed no significant differences at either PND15 or adult ages (Fig. 6).

Synaptic densities in the proximal, middle, and distal regions of stratum radiatum. To test whether the differences in synaptic densities measured between PND15 and adults might have re- 


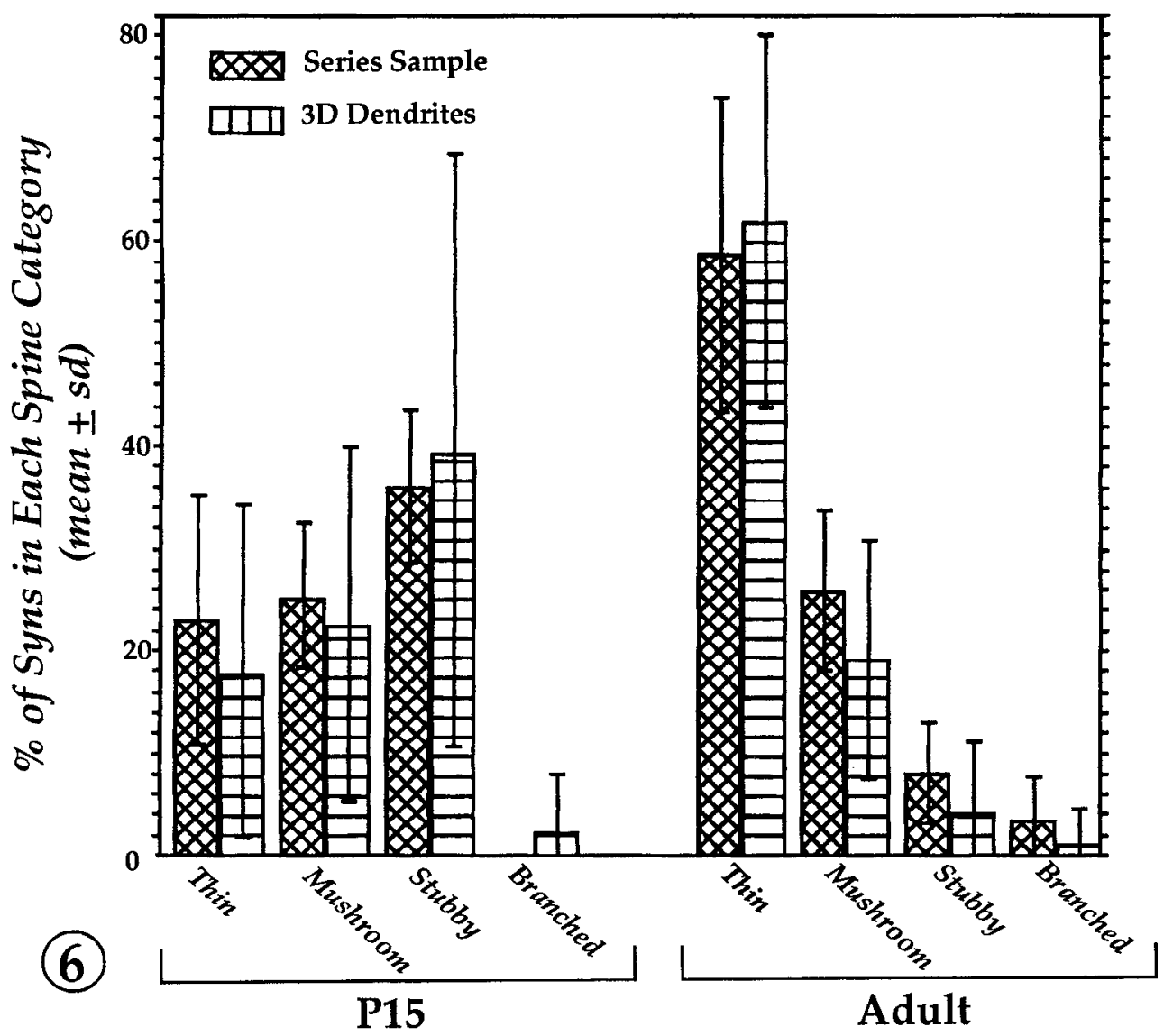

Figure 6. Direct comparison between the relative percentages of different synapses occurring on the cross- and obliquely sectioned dendrite population in the series sample with the percentages of different synapses occurring along the reconstructed dendritic segments ( $3 D$ Dendrites). Not graphed here, but included in the total percentages, are dendritic spine origins occurring on the last one to five serial sections of the reconstructed dendritic segments that were too incomplete to identify by shape (15\% of the PND15 origins, $11 \%$ of the adult origins), and shaft synapses ( $2 \%$ of the PND1 5 origins, and $0.8 \%$ of the adult origins). sulted from shifts in the relative positioning of the samples within stratum radiatum, two zones referred to as "middle" and "distal" were photographed on single sections to bracket the series samples at $192 \pm 8 \mu \mathrm{m}$ and $264 \pm 8 \mu \mathrm{m}$ from the pyramidal cell bodies. A third, "proximal" zone was positioned an extreme distance from the series samples at $72 \pm 8 \mu \mathrm{m}$ into stratum radiatum from the pyramidal cell bodies. Twelve proximal, 11 middle, and 12 distal zones were photographed at $10,000 \times$ from one PND1 5 animal, for total HN areas of 880,795 and $862 \mu \mathrm{m}^{2}$ in each zone, respectively. For the $\mathrm{d} 70$ adult, 11 proximal, 12 middle, and 13 distal zones were photographed on single sections, for total HN areas of 859,881 and $1038 \mu \mathrm{m}^{2}$ in each zone, respectively. Synpases located on spine heads or dendritic shafts were counted if a cross-, obliquely, or tangentially sectioned PSD was visible. For both PND15 and adults, the density of synapses on dendritic shafts and spine heads were the same across the proximal, middle, and distal zones in stratum radiatum and the mean densities were not significantly less than those obtained by the series sample analyses.

Comparison of series sample and single section analyses for detection of dendritic spine shapes. All of the longitudinally sectioned dendritic spines occurring in the single sections from the proximal, middle, and distal zones were classified, where possible, by the critcria of Figure 3 above and did not differ significantly across stratum radiatum in the frequencies of identifiable spines in each shape category. The samples from the middle zone of stratum radiatum were compared with the series samples (Fig. 7). There was great variability across the single sections as to which spine shapes could be identified. Only $26 \%$ of the PND15 spines and $8 \%$ of the adult spines appearing in the single sections could be assigned with confidence to a shape category. When compared to the series sample, only $4 \%$ of the thin and $20 \%$ of the mushroom spines were detected at both ages. In contrast, $24 \%$ (PND15) and $42 \%$ (adult) of the stubby spines were detected in the single sections.

Comparison of series sample analyses with single section estimates of synaptic density from other studies. In another single scction study of stratum radiatum in hippocampal area CA1 from adult male rats of the same strain and age, only 20 synapses $/ 100 \mu \mathrm{m}^{2}$ of total sample area were detected (Chang and Greenough, 1984). Our higher value of 55 synapses $/ 100 \mu \mathrm{m}^{2}$ of HN could be accounted for by (1) the increased confidence that viewing through serial sections gave us to include the edges of synapses and synapses that were sectioned obliquely or tangentially, and (2) the decrease in sample area caused by the $\mathrm{HN}$ adjustment to account for the nonuniform occurrence of some structures on the reference sections. To determine how much the serial viewing improved our detection of synapses, we recomputed the mean synaptic densities per total inhomogeneous sample area as $22 \pm 5 / 100 \mu \mathrm{m}^{2}$ and $44 \pm 7 / 100 \mu \mathrm{m}^{2}$ for PND15 and adults, respectively. Thus, an increase in detection of 24 synapses $/ 100 \mu \mathrm{m}^{2}$ was obtained by serial viewing for the adults, with an additional $11 / 100 \mu \mathrm{m}^{2}$ obtained by the $\mathrm{HN}$ adjustment. Lee et al. (1980) reported a density of 39 synapses $/ 100 \mu \mathrm{m}^{2}$ in adult rats of a different strain by positioning the photographic field to exclude the cytoplasm of large dendrites, and thus this value should be compared with the 55 synapses $/ 100 \mu \mathrm{m}^{2}$ of $\mathrm{HN}$ we obtained. These comparisons show that serial viewing accounts for more than twice as much of the increase in synaptic density as the adjustment for inhomogeneity in the neuropil. 
Figure 7. Comparison of single section and series sample analyses for detecting spines with different shapes in the neuropil.

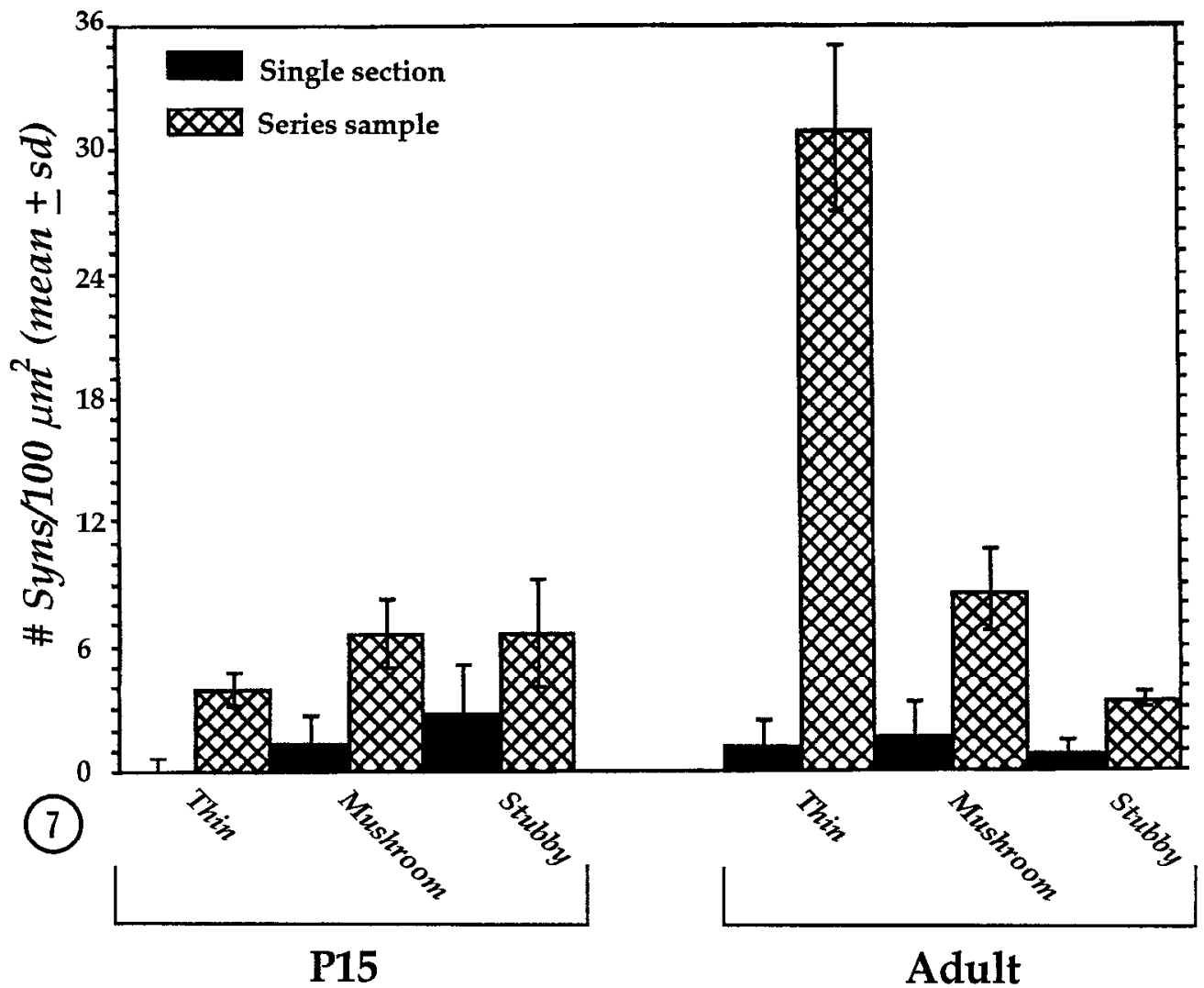

well-laminated mature spine apparatuses that were found most frequently in mushroom spines $\left(\chi^{2}=171\right.$, df $\left.=2, p<0.001\right)$ having perforated PSDs $\left(\chi^{2}=202, \mathrm{df}=2, p<0.001\right)$ (Fig. 8). At PND15, 2\% of the spines contained pre-spine apparatuses, too few to test statistically their association with stubby and mushroom spines with perforated PSDs.

The mean PSD areas changed significantly between PND15 and adult ages only for the thin and the stubby spines, with both types decreasing in average size (Table 3 ). Within age PND15, the PSD areas on the thin spines were less than those on the stubby spines $(p<0.00001)$, which in turn were equal to the macular PSDs on mushroom spines and less than the perforated PSDs on mushroom spines $(p<0.005)$. Within the adult ages, tween thin and mushroom categories each had a single perf ration in the PSDs. For the adults $15 \%$ of the spines contained

\begin{tabular}{|c|c|c|c|}
\hline Category & $\begin{array}{l}\text { PND15 } \\
(\text { mean } \pm \text { SD) }\end{array}$ & $\begin{array}{l}\text { Adult } \\
(\text { mean } \pm \mathrm{SD})\end{array}$ & $p$ \\
\hline Thin spines & $0.07 \pm 0.03$ & $0.05 \pm 0.03$ & $<0.001$ \\
\hline Stubby spines & $0.14 \pm 0.11$ & $0.07 \pm 0.05$ & $<0.001$ \\
\hline Mushroom spines, macular PSD & $0.15 \pm 0.09$ & $0.15 \pm 0.06$ & NS \\
\hline Mushroom spines, perforated PSD & $0.26 \pm 0.07$ & $0.27 \pm 0.13$ & NS \\
\hline Branched spines & $0.06 \pm 0.01$ & $0.08 \pm 0.07$ & - \\
\hline Asymmetric shafts & $0.15 \pm 0.10$ & $0.16 \pm 0.15$ & NS \\
\hline Symmetric shafts & $0.23 \pm 0.19$ & $0.12 \pm 0.09$ & NS \\
\hline
\end{tabular}

At PND15 189 PSDs were reconstructed, and 184 were classified as thin $(n=47)$, stubby $(n=53)$, mushroom-macular $(n=31)$, mushroom-perforated $(n=10)$, or branched $(n=2)$ dendritic spines, and asymmetric $(n=30)$ or symmetric $(n=10)$ dendritic shaft synapses. For the adults, 465 PSDs were reconstructed, and 463 were classified, as thin ( $n=$ $249)$, stubby $(n=21)$, mushroom-macular $(n=52)$, mushroom-perforated $(n=86)$, or branched $(n=25)$ dendritic spines, and asymmetric $(n=17)$ or symmetric $(n=13)$ dendritic shaft synapses. At PND15, six PSDs, and for the adults, two PSDs, were excluded either because the postsynaptic identity was ambiguous or because part of a PSD was obscured on one section. 


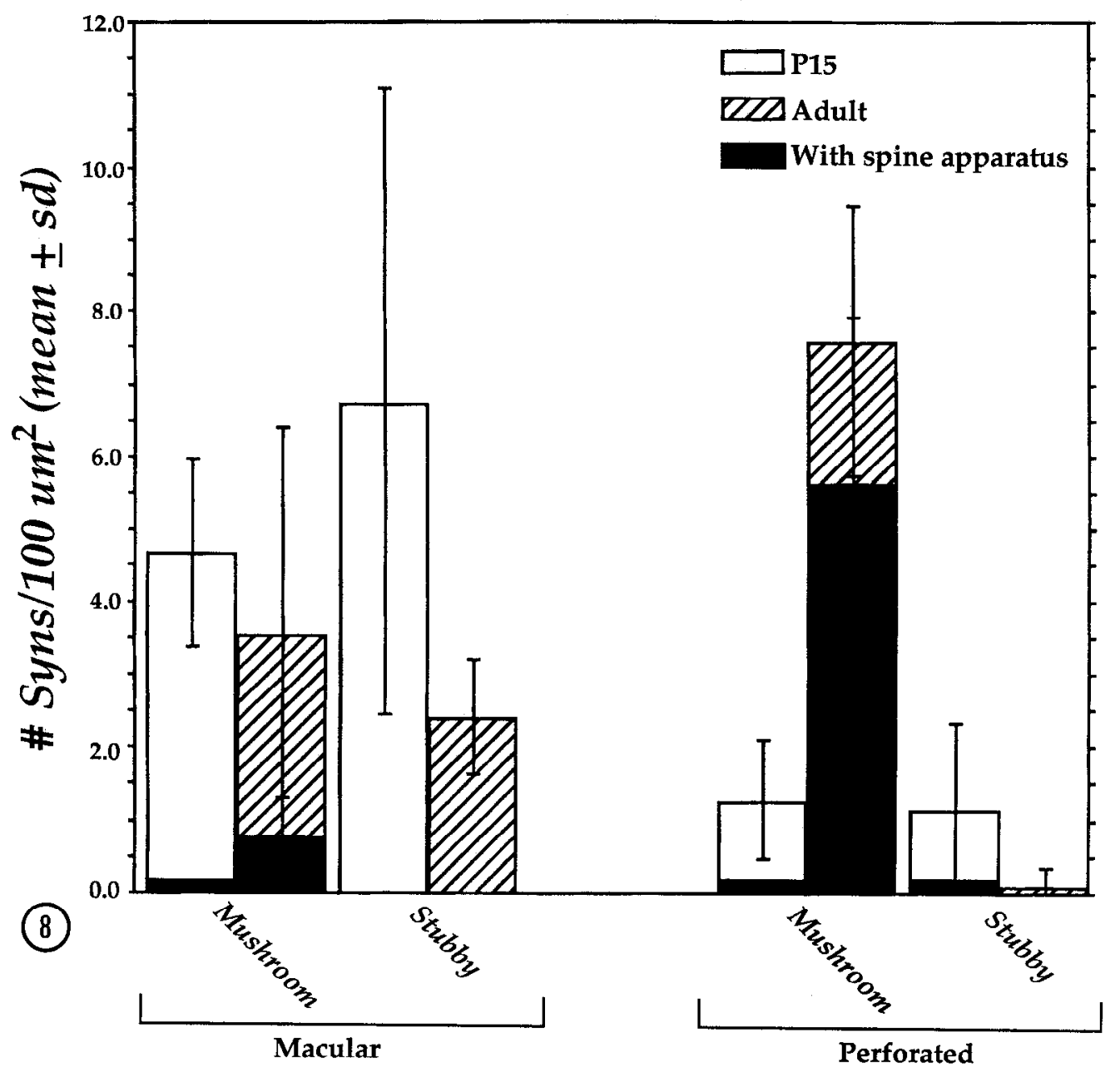

Figure 8. Relative frequencies in the series samples of macular and perforated synapses on dendritic spines with and without spine apparatuses. The frequency of spines without spine apparatuses (PNDI 5 and adult) are stacked on top of those with spine apparatuses (solid bars), so that the full height of each bar illustrates the total density in the neuropil of mushroom or stubby spines with macular or perforated PSDs. Thin and branched spines are not graphed because they had no spine apparatuses.
PSD areas on the thin spines were less than those on the stubby spines $(p<0.01)$, which in turn were less than both the macular $(p<0.0001)$ and the perforated $(p<0.0000001)$ PSDs on the mushroom spines. At both ages, the PSD areas on branched spines were not significantly different from those on thin spines.

Three-dimensional reconstructions of randomly selected dendritic spines in each shape category. Micrographs of the reference section of randomly selected spines in each shape class are il- lustrated in Figure 9, and their complete reconstructions are in Figure 10. Longitudinally sectioned stubby spines (Fig. 9a) were readily identified by shape on a single section, but were indistinguishable from the heads of mushroom or thin spines if cross sectioned (Fig. 9b). Single sections of mushroom spine heads were frequently larger than thin spine heads in the same field (Fig. $9 c ; e$, labeled; $f$, though portions of their heads also were often indistinguishable from thin or stubby spines in the same

Figure 9. Reference sections of spines that are fully reconstructed in Figure 10. $a$, PND15 stubby spine $(S)$ reconstructed in Figure $10 a$ and a neighboring stubby spine (arrowhead) on the same dendritic segment. $b$, Adult stubby spine head $(S)$ reconstructed in Figure $10 b$ is indistinguishable from other mushroom or thin spine heads on a single thin section. $c$, PND15 mushroom spine head $(M)$ reconstructed in Figure $10 c$. $d$, Adult mushroom spine $(M)$ reconstructed in Figure 10d.e. PND15 mushroom spine $(M)$ that is reconstructed in Figure $10 e$ shares its presynaptic varicosity with the synapse of another mushroom spine (small arrowheads) whose head and PSD (large arrowhead) are cut en face and are difficult to recognize on a single section. $f$, Adult mushroom spine $(M)$ reconstructed in Figure $10 f$ and thin $(T)$ spine reconstructed in Figure $10 h$. A small portion of the head (circle) and PSD (arrowhead) of another thin spine was identified by viewing it on adjacent sections. $g$, PND15 thin spine ( $T$ ) reconstructed in Figure $10 \mathrm{~g}$. $h$ and $i$, Sections 30 and 28 , respectively, of a dendritic segment that was reconstructed along its length, thereby revealing the presence of a filopodium $(F)$ that is reconstructed in Figure 10i, located next to a stubby dendritic spine (arrowhead). $j$, Section 36 of the branched spine reconstructed in Figure $10 j$. The origin of this branched spine $(B 1)$ was longitudinally sectioned by the reference section, though initially we did not recognize branch two $(B 2)$ of this spine because the synapse was not evident until section 42 . $B 2$ could have been an obliquely sectioned portion of the parent dendrite. $k$, Subsequent reconstruction revealed a third branch $(B 3)$ whose synapse shared a population of presynaptic axonal vesicles with the head of a mushroom dendritic spine (arrowhead). $l$, Synpase of $B 2$ in section 43 of this series. Scale bar in $l$ is for $a-l$.

Figure 10. Three-dimensional reconstructions of dendritic spines from the series samples. $a$ and $b$, PND15 and adult stubby spines illustrated in Figure 9, $a$ and $b . c$, PND15 mushroom spine in Figure $9 c . d$, Adult mushroom spine at the mushroom/thin borderline, in Figure $9 d$. $e$ and $f$, PND 15 and adult mushroom spines in Figure $9, e$ and $f . g$ and $h$, PND 15 and adult thin spines in Figure 9, $g$ and $f$, respectively. $i$, PND15 filopodium in Figure 9, $h$ and $i . j$, Adult branched dendritic spine and three different presynaptic axonal varicosities (dark green) synapsing with each head. Two of these presynaptic boutons also made synapses with the heads of other mushroom spines, portions of which are reconstructed and displayed. All spines are gold, and the PSDs are light blue. The origins of the spines with their parent dendrites are at the left side of each panel. The scale is the same as Figure 9. 

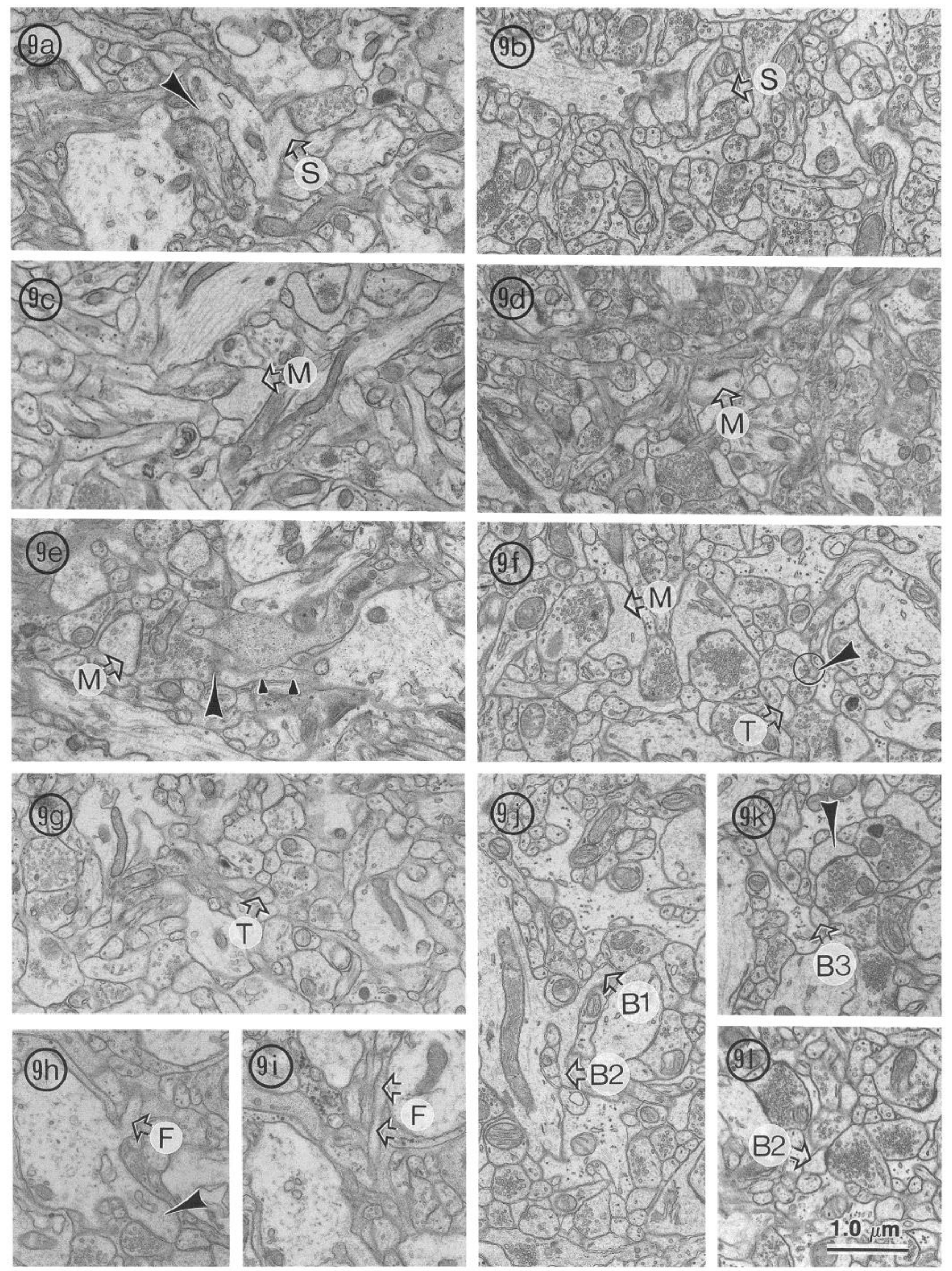


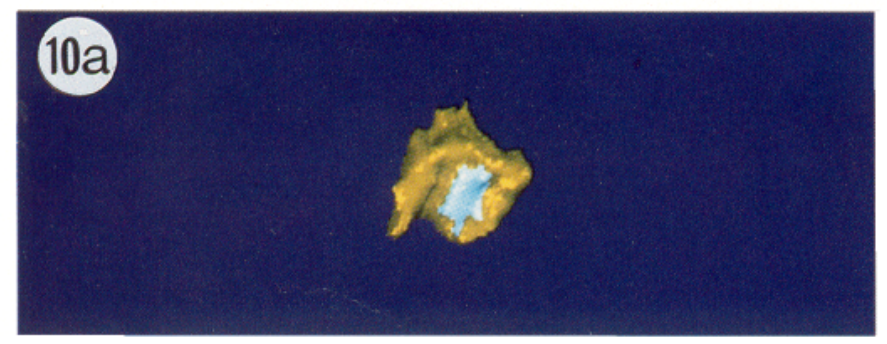

(10b)
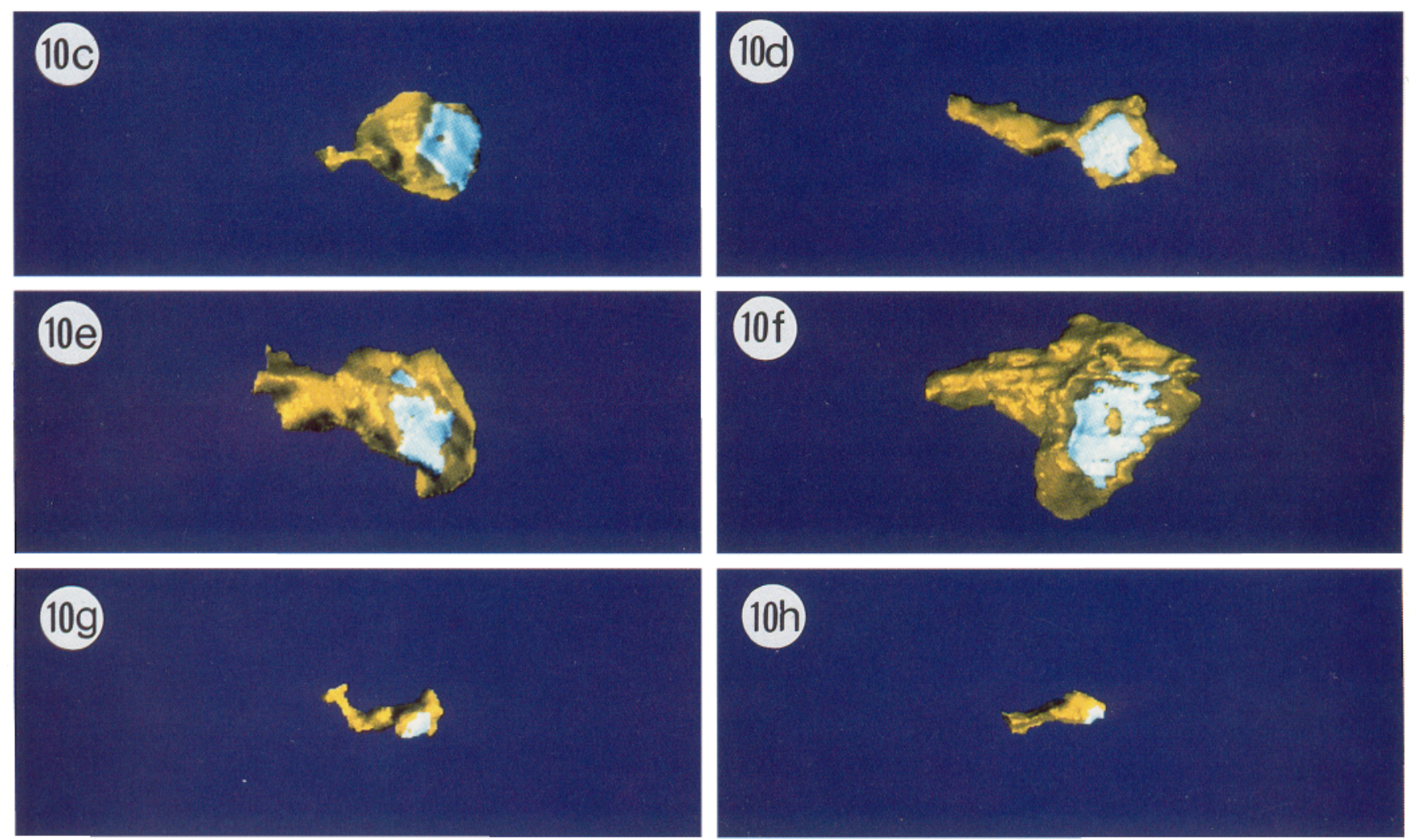

10h
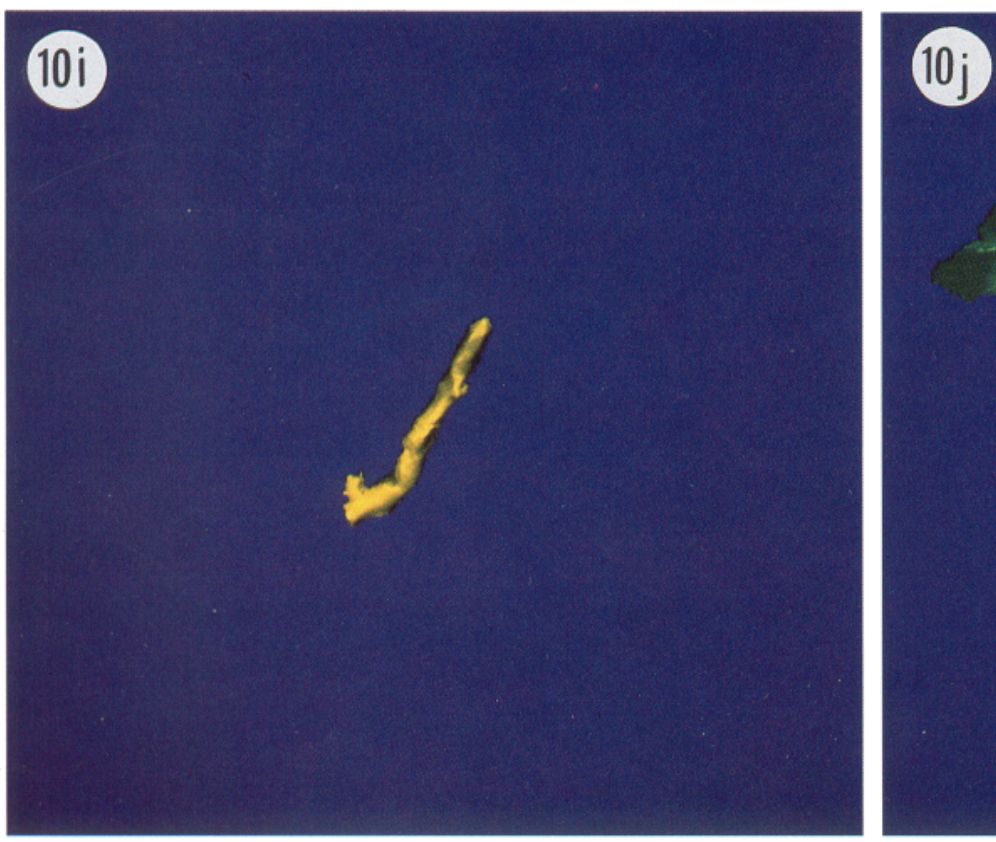

\section{B}

10d
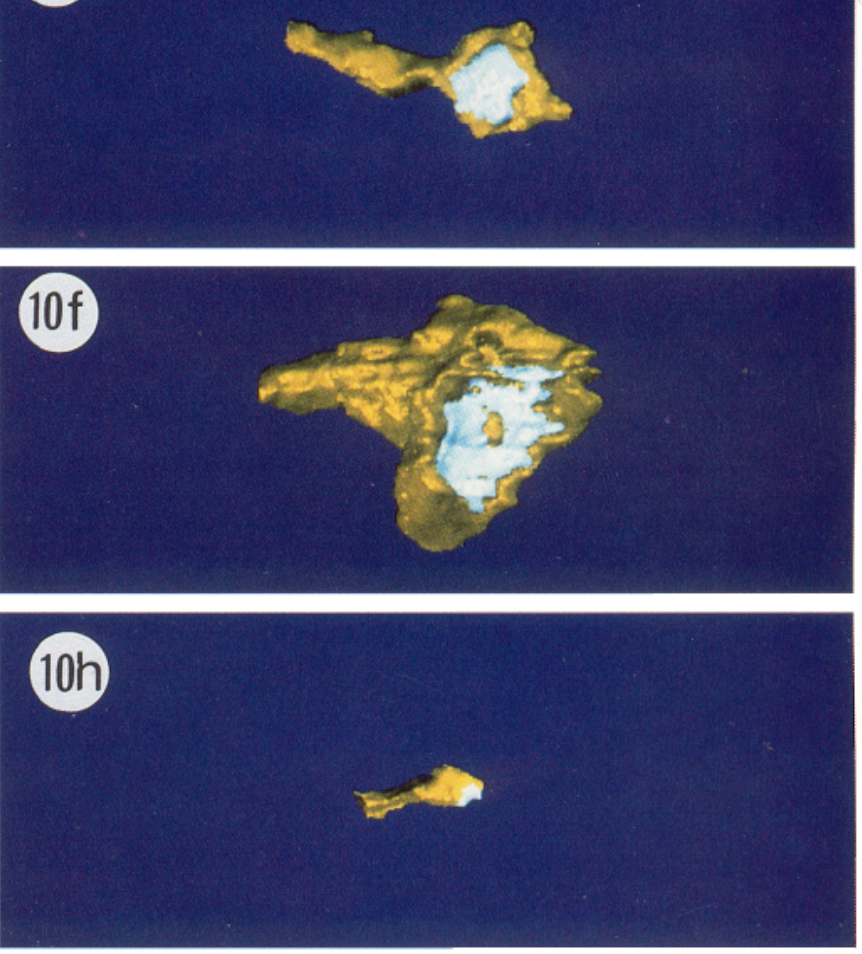

$10 \mathrm{j}$

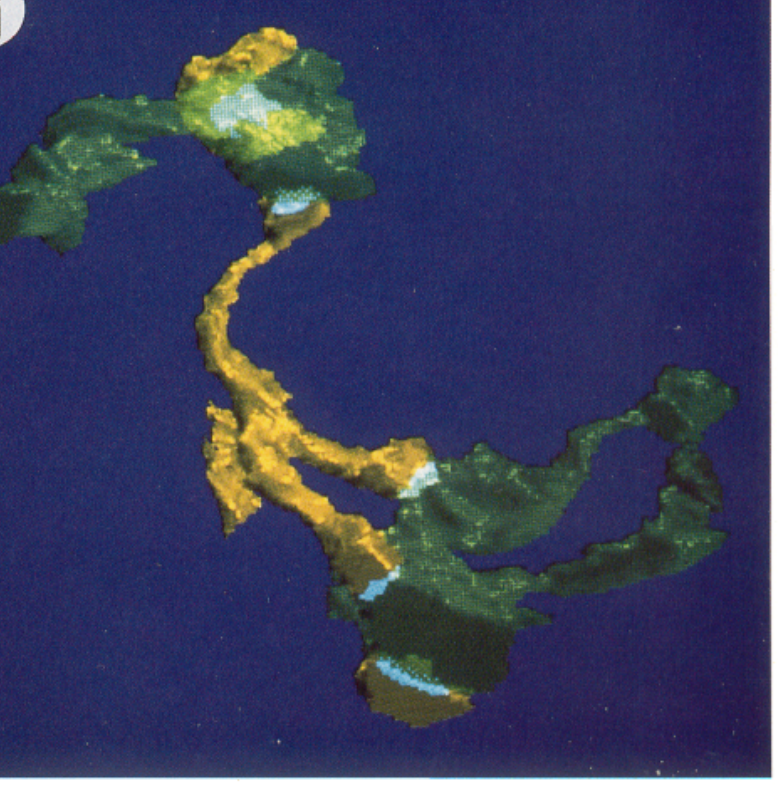


Table 4. Comparison of complete spine dimensions by shape class from three-dimensional reconstructions of spines in the PND15 and adult sample fields

\begin{tabular}{|c|c|c|c|}
\hline Spine class dimensions & $\begin{array}{l}\text { PND15 } \\
(\text { mean } \pm S D)\end{array}$ & $\begin{array}{l}\text { Adult } \\
(\text { mean } \pm \text { SD) }\end{array}$ & $p$ \\
\hline Stubby & $(n=6)$ & $(n=8)$ & \\
\hline Total surface area $\left(\mu \mathrm{m}^{2}\right)$ & $0.95 \pm 0.48$ & $0.45 \pm 0.14$ & $<0.05$ \\
\hline of PSD & $0.15 \pm 0.09$ & $0.07 \pm 0.02$ & NS \\
\hline PSD/total & $0.16 \pm 0.03$ & $0.16 \pm 0.05$ & NS \\
\hline Total volume $\left(\mu \mathrm{m}^{3}\right)$ & $0.11 \pm 0.07$ & $0.03 \pm 0.01$ & $<0.03$ \\
\hline Total length $(\mu \mathrm{m})$ & $0.65 \pm 0.38$ & $0.44 \pm 0.15$ & NS \\
\hline to PSD & $0.37 \pm 0.31$ & $0.29 \pm 0.16$ & NS \\
\hline Neck diameter $(\mu \mathrm{m})$ & $0.43 \pm 0.07$ & $0.32 \pm 0.13$ & NS \\
\hline Dendrite diameter $(\mu \mathrm{m})$ & $0.81 \pm 0.29$ & $0.78 \pm 0.36$ & NS \\
\hline Mushroom & $(n=7)$ & $(n=9)$ & \\
\hline Total surface area $\left(\mu \mathrm{m}^{2}\right)$ & $1.70 \pm 0.70$ & $2.70 \pm 0.93$ & $<0.05$ \\
\hline of PSD & $0.21 \pm 0.10$ & $0.30 \pm 0.10$ & NS \\
\hline of head & $1.50 \pm 0.62$ & $2.40 \pm 0.92$ & $<0.05$ \\
\hline PSD/head & $0.14 \pm 0.03$ & $0.18 \pm 0.15$ & NS \\
\hline of neck & $0.26 \pm 0.29$ & $0.25 \pm 0.12$ & NS \\
\hline Total volume $\left(\mu \mathrm{m}^{3}\right)$ & $0.18 \pm 0.09$ & $0.29 \perp 0.13$ & NS \\
\hline of head & $0.16 \pm 0.08$ & $0.27 \pm 0.13$ & NS \\
\hline of neck & $0.21 \pm 0.03$ & $0.02 \pm 0.01$ & NS \\
\hline Total length $(\mu \mathrm{m})$ & $0.95 \pm 0.30$ & $1.50 \pm 0.25$ & $<0.001$ \\
\hline to PSD & $0.81 \pm 0.22$ & $1.10 \pm 0.28$ & $<0.04$ \\
\hline of neck & $0.36 \pm 0.25$ & $0.43 \pm 0.21$ & NS \\
\hline Neck diameter $(\mu \mathrm{m})$ & $0.21 \pm 0.12$ & $0.20 \pm 0.07$ & NS \\
\hline Dendrite diameter $(\mu \mathrm{m})$ & $0.83 \pm 0.37$ & $0.81 \pm 0.24$ & NS \\
\hline Thin & $(n=5)$ & $(n=8)$ & \\
\hline Total surface area $\left(\mu \mathrm{m}^{2}\right)$ & $0.80 \pm 0.26$ & $0.59 \pm 0.29$ & NS \\
\hline of PSD & $0.06 \pm 0.03$ & $0.05 \pm 0.02$ & NS \\
\hline of head & $0.44 \pm 0.26$ & $0.40 \pm 0.15$ & NS \\
\hline PSD/head & $0.16 \pm 0.05$ & $0.10 \pm 0.06$ & NS \\
\hline of neck & $0.43 \pm 0.26$ & $0.21 \pm 0.17$ & NS \\
\hline Total volume $\left(\mu \mathrm{m}^{3}\right)$ & $0.05 \pm 0.03$ & $0.04 \pm 0.02$ & NS \\
\hline of head & $0.03 \pm 0.02$ & $0.03 \pm 0.15$ & NS \\
\hline of neck & $0.02 \pm 0.01$ & $0.01 \pm 0.01$ & NS \\
\hline Total length $(\mu \mathrm{m})$ & $1.40 \pm 0.39$ & $0.98 \pm 0.42$ & NS \\
\hline to PSD & $1.30 \pm 0.46$ & $0.74 \pm 0.36$ & $<0.04$ \\
\hline of neck & $0.90 \pm 0.24$ & $0.51 \pm 0.34$ & NS \\
\hline Neck diameter $(\mu \mathrm{m})$ & $0.13 \pm 0.05$ & $0.10 \pm 0.03$ & NS \\
\hline Dendrite diameter $(\mu \mathrm{m})$ & $0.70 \pm 0.33$ & $0.62 \pm 0.26$ & NS \\
\hline Branched & $(n=0)$ & $(n=2)$ & - \\
\hline Total classified & 18 & 27 & - \\
\hline Total borderline & 6 & 3 & - \\
\hline
\end{tabular}

Borderline spines shared characteristics of more than one class; for PND15 the borderline shapes included one stubby/thin, one stubby/mushroom, four mushroom/thin; for the adults borderline shapes included two shaft/stubby and one thin/mushroom.

field (Fig. $9 d ; e$, arrowhead). Thin spine heads were always quite small (Fig. $9 f$, labeled; $g$ ) and thus often required viewing through adjacent sections to confirm the presence of an edge of their synapse on the reference section (Fig. 9f, circle). Two sections of a filopodium that occurred on one of the reconstructed dendritic segments are shown in Figure $9, h$ and $i$, and it is reconstructed in Figure 10i. All of the processes located adjacent to both of the reconstructed filopodia were viewed through serial sections to confirm that no nascent synapses were present.

In the adult, two spines that were originally classified as thin were found instead to be branched spines through complete reconstructions (Figs. $9 j-l, 10 j$ ). These branched spine reconstructions prompted the reevaluation of all dendritic spines in the series samples to ascertain whether a branch occurred along their length. Thus, the values for branched spines presented above in Figure $5 a$ were excluded from the thin category and account for all branched spines that had the PSD of at least one head on the reference section of the series sample.

Dimensions of reconstructed dendritic spines. The dimensions were computed from the complete reconstructions and are presented in Table 4 in sufficient detail to allow predictions of theoretical models to be tested. Fixation-induced shrinkage or swelling does not seem to account for differences in spine, synapse, and dendrite morphologies from the PND15 and adult samples. At both ages, all structures were well preserved as judged by continuous plasmalcmmac, unswollen mitochondria, continuous microtubules, nonvacuolated cytoplasm, and complete synapses. In the absence of specific ultrastructural evidence for fixation-induced changes, no correction was introduced to account for this potential artifact. The mean areas of PSDs on the reconstructed dendritic spines from each shape class were the same as the means by shape class in the series sample, indicating that random selection of spines for reconstruction obtained spines that were probably representative of their shape classes. Within a shape category, it is remarkable how similar the dimensions remained between PND1 5 and adult ages. Stubby spines had more volume and surface area at PND15 than in adults, though their other dimensions remained unchanged. Mushroom spines had less surface area and length at PND15 than in adults, but other dimensions did not differ significantly, though these were more variable in size and shape than either stubby or thin spines. Only the length to the PSD of the thin spines differed significantly between these two ages. At both PND1 5 and adult ages, the PSD area on all spines is well correlated with the spine head volume and surface area but less well correlated with spine neck volume and surface area (Table 5). Spine lengths and diameters as well as the diameter of the parent dendrite are not correlated with the area of the PSD at either age.

Reliability of spine shape criteria for distinguishing stubby, mushroom, and thin spines. Comparison of dimensions of the spine head, total spine length, and neck diameters served to distinguish whether the qualitative criteria used to classify spines were sufficient to distinguish them quantitatively. The ratio of spine head volume to neck diameter should distinguish mushroom from thin and stubby spines, while the ratio of the total spine length to neck diameter should distinguish thin from stubby spines. Mushroom spines were not completely distinguished from thin spines at PND15 by the ratio of spine head volume to neck diameter (Fig. $11 a$ ). In contrast, for the adults the ratio of head volume to neck diameter formed three discrete clusters of thin, mushroom, and stubby spines (Fig. 11b). At both ages, thin spines were distinguished from stubby spines by the total length compared to neck diameter (data not shown). Thus, both qualitative and quantitative distinctions between spine shape categories are more distinct in adults than at PND15.

\section{Modeling the effect of spine neck dimensions on synaptic charge transfer}

The dimensions of the mushroom spine necks were estimated from edited reconstructions as illustrated in Figure 12, $a$ and $b$ (insets), because their large heads do not contribute to charge reduction. The total length of stubby and thin spines was used 

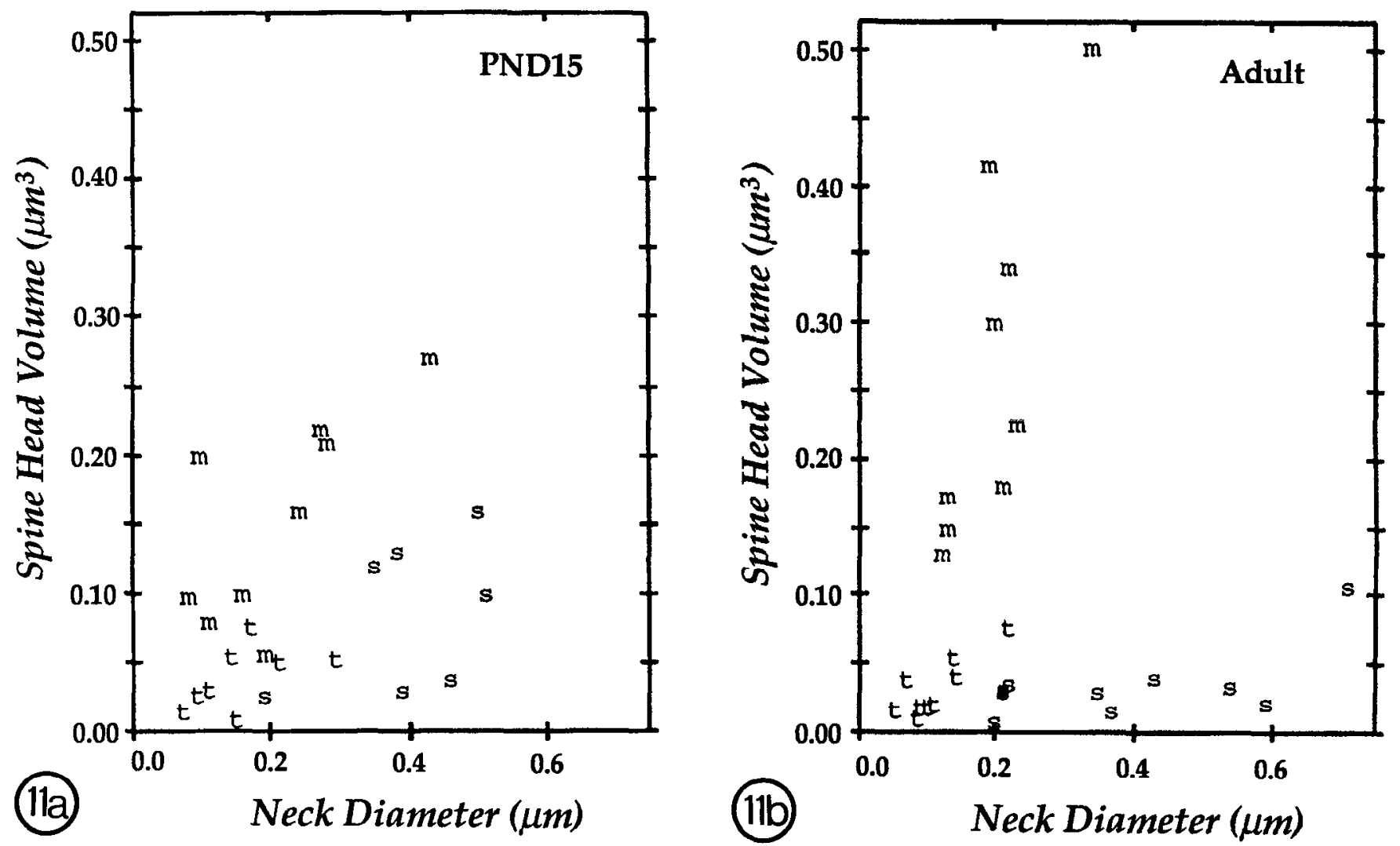

Figure 11. Quantitative index of spine shapes at PND15 (a) and adult (b) ages. For the adults, but not at PND15, the ratio of spine head volume to spine neck diameter separates all three shape categories of stubby $(s)$, mushroom $(m)$, and thin $(t)$ spines from one another. The borderline shapes delineated in the notes of Table 4 are plotted here as the shape they most resembled, and occur in the region of overlap between the shapes, especially at PND15.

to evaluate the effect of spine neck constriction on charge transfer, because by definition these head diameters are not grossly larger than the neck diameters. Some dendritic spines at both ages cause more than $5 \%$ reduction in synaptic charge transfer to the parent dendrite if the synaptic conductance $G_{\max }$ is $1 \mathrm{nS}$ (Fig. 12a,b, data points to the left of the solid lines). These spines are mostly of the thin shape category. However, all of the thin and about half of the mushroom and stubby spines at both ages

Table 5. Range in spine dimensions and correlation with the surface area of the PSD

\begin{tabular}{|c|c|c|c|c|c|c|c|c|}
\hline & \multicolumn{4}{|c|}{ PND15 } & \multicolumn{4}{|l|}{ Adult } \\
\hline & $\overline{\text { Min }}$ & $\operatorname{Max}$ & $r$ & $p$ & Min & Max & $r$ & $p$ \\
\hline PSD surface area $\left(\mu \mathrm{m}^{2}\right)$ & 0.005 & 0.35 & - & - & 0.008 & 0.54 & - & - \\
\hline \multicolumn{9}{|c|}{ Total spine } \\
\hline Surface area $\left(\mu \mathrm{m}^{2}\right)$ & 0.16 & 2.50 & 0.90 & $<0.0005$ & 0.13 & 4.50 & 0.89 & $<0.0005$ \\
\hline Volume $\left(\mu \mathrm{m}^{3}\right)$ & 0.008 & 0.32 & 0.83 & $<0.0005$ & 0.004 & 0.56 & 0.93 & $<0.0005$ \\
\hline Length $(\mu \mathrm{m})$ & 0.19 & 1.96 & 0.26 & $<0.05$ & 0.19 & 2.46 & 0.34 & $<0.005$ \\
\hline Length to PSD $(\mu \mathrm{m})$ & 0.07 & 1.95 & -0.32 & $<0.01$ & 0.09 & 2.13 & 0.13 & NS \\
\hline \multicolumn{9}{|l|}{ Spine head } \\
\hline Surface area $\left(\mu \mathrm{m}^{2}\right)$ & 0.16 & 2.25 & 0.93 & $<0.0005$ & 0.15 & 4.21 & 0.76 & $<0.0005$ \\
\hline Volume $\left(\mu \mathrm{m}^{3}\right)$ & 0.008 & 0.27 & 0.87 & $<0.0005$ & 0.003 & 0.55 & 0.91 & $<0.0005$ \\
\hline \multicolumn{9}{|l|}{ Spine neck } \\
\hline Surface area $\left(\mu \mathrm{m}^{2}\right)$ & 0.04 & 0.82 & 0.24 & $<0.05$ & 0.02 & 0.89 & 0.11 & NS \\
\hline Volume $\left(\mu \mathrm{m}^{3}\right)$ & 0.002 & 0.10 & 0.29 & $<0.05$ & 0.0004 & 0.07 & 0.38 & $<0.0005$ \\
\hline Length $(\mu \mathrm{m})$ & 0.09 & 1.29 & 0.05 & NS & 0.08 & 1.67 & 0.08 & NS \\
\hline Diameter $(\mu \mathrm{m})$ & 0.05 & 0.51 & 0.25 & $<0.05$ & 0.04 & 0.71 & 0.30 & $<0.05$ \\
\hline Dendrite diameter $(\mu \mathrm{m})$ & 0.23 & 1.60 & -0.05 & NS & 0.24 & 1.6 & 0.19 & NS \\
\hline
\end{tabular}

All dendritic spines that have been reconstructed at each age are included here for a total at PND15 of 55 (24 randomly selected from the series samples, 31 from other reconstructions that were not randomly chosen) and for a total in the adult of 130 ( 30 randomly selected from the series samples and 100 from earlier reconstructions by Harris and Stevens, 1989). Min, minimum value; Max, maximum value; $r$, correlation with the PSD area; $p$, probability that the correlation is not different from $0 ; \mathrm{NS}$, correlation is not significantly different from 0 . 

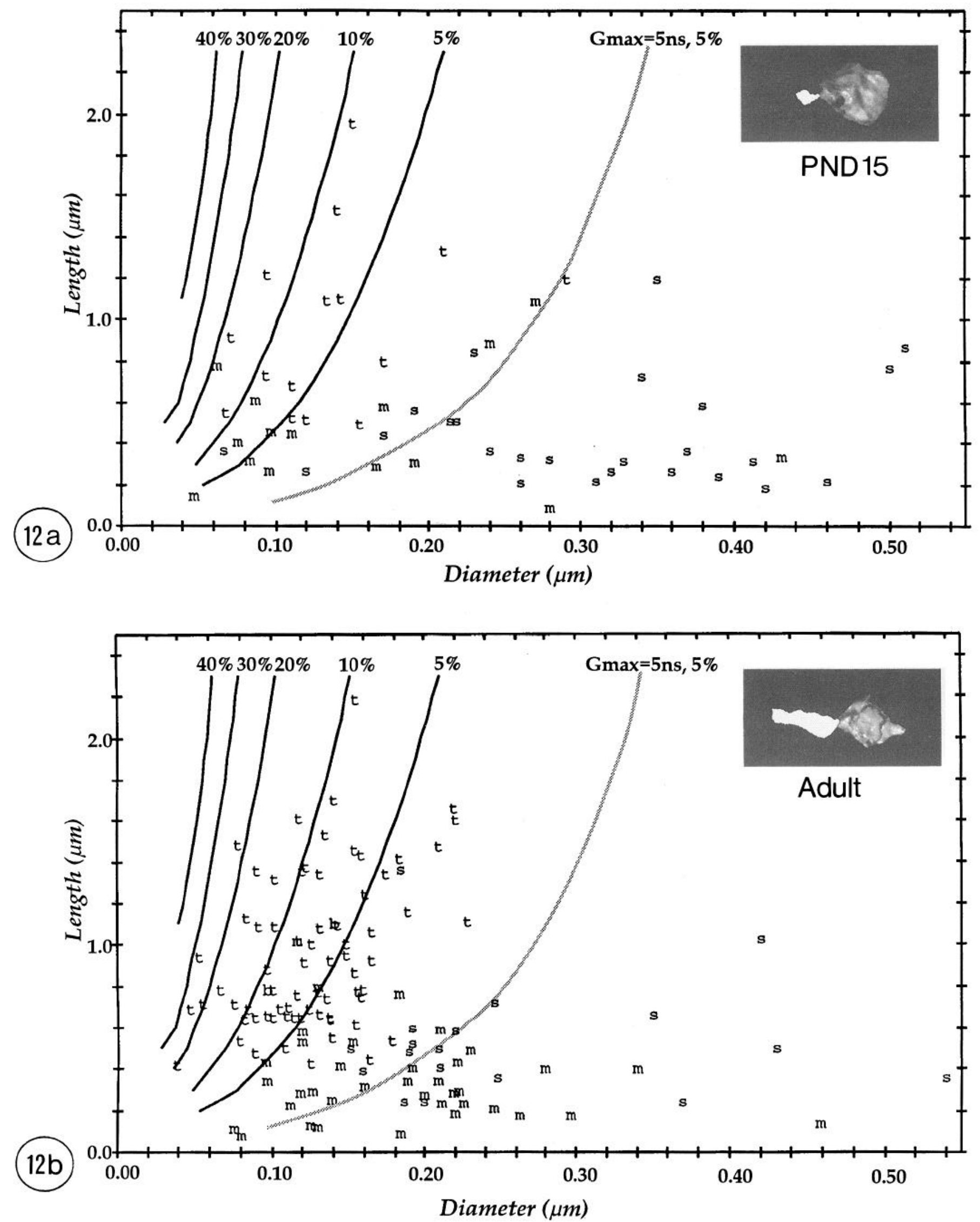

Figure 12. The effect of spine neck constriction on the theoretical percent reduction in charge transfer from the synapse to the parent dendrite. Spines falling on the theoretical lines reduce charge transfer by the percentage listed at the top of the line, while spines falling to the left or right of the lines reduce charge transfer by more or less than percentage of the line, respectively. For these simulations, $G_{\max }$ values of $1 \mathrm{nS}$ (solid lines) and 
cause more than $5 \%$ rcduction in synaptic charge transfer if $G_{\max }$ is $5 \mathrm{nS}$ (Fig. 12a,b, data points to the left of the shaded line).

\section{Discussion}

Due to the large number, small size, and variability in shape of synapses and dendritic spines, a new approach was developed to distinguish growth and differentiation of existing synapses from the addition of new synapses to the neuropil. The series sample analysis revealed a doubling in synaptic density in stratum radiatum of hippocampal area CA1 between the PND15 and adult ages. This age-related doubling did not occur uniformly across all spine and synapse geometries. No change occurred in the density of dendritic shaft synapses or mushroom spines with macular PSDs. In sharp contrast, the density of thin spines, mushroom spines with perforated PSDs, and branched spines all increased by about fourfold, while the density of stubby spines decreased by more than half. A single section analysis did not detect any of these age-related changes. In fact, the more uniformly shaped stubby spines were detected most readily on single thin sections at both ages, though they are the least prevalent shape in the adults. Preliminary results using the series sample analysis in PND7 hippocampal area CA1 revealed that most of the synapses are on dendritic shafts, with occasional synapses on stubby and mushroom spines, but none on thin spines (Harris et al., 1987, 1989). Together, these findings suggest that shaft synapses form first and may give rise to stubby dendritic spines, which in turn may form mushroom, thin, and/ or branched dendritic spines with constricted necks.

The doubling in synaptic density occurs across the entire width of stratum radiatum and along the lengths of individual dendrites coursing through the ncuropil. Thus, to our first qucstion inquiring whether the series sample reflects the distribution of spines along individual dendrites, the answer is a cautious, yes, on average. However, individual dendritic segments could be found to have more or less than the average percentage of dendritic spines in each category as evidenced by the standard deviations in Figure 6. In single section studies, Schwartzkroin et al. (1982) found a doubling in synapse density in stratum radiatum of the rabbit area CA1 between PND8 and PND28, and Pokorny and Yamamoto (1981) detected a near doubling in total synapse density in stratum lacunosum of rat area CAl between PND15 and PND48. However, in neither of these studies could the frequency of spines or synapses with different geometries be evaluated. The frequency of spines previously estimated from light microscopy of Golgi impregnations (Minkwitz, 1976; Pokorny and Yamamoto, 1981; Schwartzkroin et al., 1982) is about half that detected along the dendrites rcconstructed here through serial EM, probably because the dark precipitate in the Golgi-impregnated dendrites obscures all or part of many spines (Feldman and Peters, 1979).

In our previous studies, spiny dendrites were selected for serial EM by the presence of a longitudinally sectioned spine attached to the dendrite in the first section observed (Harris and Stevens,
$1987,1988,1989)$. Here, our preliminary findings suggested that the dendrites with attached spines tend to be more spiny than the mean of randomly selected spiny dendrites, some of which lack attached spines on the reference section (Neukermans and Harris, unpublished observations). Therefore, random selection of dendrites from the series samples was required to avoid a high bias, and it would seem prudent in future studies to rank order the dendrites by spine density before comparing across experimental treatments. In sum, single section analyses from EM and light microscopy studies from Golgi impregnations are sufficient to reveal gross changes in the total spine and synapse densities during development, but serial EM is required to delineate unambiguously any changes in the frequency of spines and synapses with different geometries.

To our second question inquiring whether spine shapes occur along a continuum or in discrete categories, the answer seems to be that it depends on the category. First, the stubby spines nearly disappear with maturation, suggesting that they may have a transitory function. Second, the mushroom spines show great variability in their dimensions, both within and between the ages, suggesting that they may occur along a continuum and undergo considerable remodeling. This capacity for remodeling is further supported by the changes in the characteristics of the spine apparatus and PSD that occur between PND15 and adult ages. At PND15, a "pre-spine apparatus," having a few sacs of SER, is found in small mushroom or large stubby spines. With age, the mushroom spine heads enlarge and acquire perforated PSDs and a well-laminated spine apparatus. Third, for the thin spines remarkably little change occurs in their dimensions, characteristics of the PSD, or the occurrence of a slender tube of SER at both ages. This consistency in structure suggests that they may be a discrete category having a relatively stable geometry, once they are formed.

The branched spines could result from synapses forming on new branches of existing spines or from the splitting of existing synapses (Nieto-Sampedro, 1982; Carlin and Siekevitz, 1983). Alternatively, shaft synapses might form adjacent to one another and give rise to spines that later appear to be branching from the same dendritic origin. The same presynaptic bouton is usually shared by many heads of individual branched spines at the mossy fiber synapses in hippocampal area CA3, suggesting that all three avenues of branch formation could occur here (Hamlyn, 1962; Chicurel and Harris, 1989). However, in hippocampal areas CA1 and dentata, the different heads of individual branched spines do not share the same presynaptic bouton, suggesting that they do not form by the splitting of existing synapses (see also Harris and Stevens, 1988, 1989; Geinisman et al., 1989).

The function of long filopodia in the immature hippocampus is unclear. It seems unlikely that they are part of a continuum in the formation of synapses on dendritic spines because PSDs and axonal varicosities are not adjacent to the filopodia anywhere along their lengths. Thus, their loss between PND15 and adult ages is unlikely to result in the elimination of a specific category of spine synapses in this brain region (see also Purpura, 1975).

$5 \mathrm{nS}$ (shaded line) are displayed. Only the 5\% reduction curve is displayed for the $5 \mathrm{nS}$ curve to illustrate the shift to the right (for a more detailed description of this simulation, see Wilson, 1984; Harris and Stevens, 1988, 1989). a, At PND15 all 55 spines that have been reconstructed are represented. $b$, For the adults, all 130 reconstructed spines are represented. Dendritic spines are labeled according to their shape classes of stubby $(s)$, mushroom $(\mathrm{m})$, thin $(t)$, and branched $(b)$ (the dimensions of only the one branch with its PSD on the reference section are represented for each of two branched spines from the adults). Insets are edited three-dimensional reconstructions of mushroom spine necks. 
An implicit assumption has been that structural characteristics of the PSD reflect the history of synaptic activation (Harris and Landis, 1986; Harris and Stevens, 1988, 1989). At both PND1 5 and adult ages, the area of the PSD is well correlated with the dimensions of the spine head but not the dimensions of the spine neck. It would seem then that the variability in PSD area and spine head volume may be associated with diffcrent levels of synaptic activity that have no parallel influence on the dimensions of the spine neck (Harris and Stevens, 1988, 1989; Chicurel and Harris, 1989). The PSD area occupies about $10-15 \%$ of the spine head surface at both PND15 and adult ages, and this ratio does not differ significantly across spine shape categories or on spines from different brain regions (Spacek and Hartmann, 1983; Wilson et al., 1983; Harris and Stevens, 1988, 1989; Chicarel and Harris, 1989). The relative constancy of this ratio may indicate that the proportion of molecules located specifically at the synapse (such as receptors, kinases, etc.) to molecules located on membrane adjacent to the synapse (such as ion channels, pumps, etc.) is also relatively constant. Perforated PSDs are thought to be a site of synaptic plasticity, as their number increases during axonal regeneration and LTP and they are required for learning in aged rats (Nieto-Sampedro et al., 1982; Desmond and Levy, 1986, 1988, 1990; Geinisman et al., 1986). The sacs of SER in the spine apparatus are thought to sequester calcium (Burgoyne et al., 1983; Fifkova et al., 1983; Andrews et al., 1988; Mignery et al., 1989), and the densestaining material between the sacs of a mature spine apparatus is thought to be of microtubular origin and possibly to serve both structural and protein synthetic roles (Westrum et al., 1980; Spacek, 1985a,b). These interpretations suggest that the parallel maturation of the spine apparatus with the occurrence of the perforated PSDs could signal an enhanced regulation of ionic fluxes and protein synthesis in the large adult mushroom spines.

The shift in predominance from spines with wide necks to spines with constricted necks could alter synaptic transmission and postsynaptic integration by the neuron. To our third question, inquiring whether spine necks are sufficiently thin and long to reduce charge transfer from the synapse, the answer is only if the conductance change occurring at the synapse were higher than has been reported for CA1 synapses (Bekkers et al., 1990), that is, in the range of $5 \mathrm{nS}$. However, evidence from physiological studies suggests that synaptic transmission is not reduced, but enhanced with maturation (Schwartzkroin and Altschuler, 1977; Schwartzkroin, 1982; Harris and Teyler, 1983, 1984).

Constricted spine necks would enhance synaptic transmission by amplifying the potential generated in the spine heads via voltage-dependent channels (Diamond et al., 1970; Koch and Poggio, 1983; Miller et al., 1985; Perkel and Perkel, 1985; Shepherd et al., 1985; Segev and Rall, 1988; Woolf et al., 1991). A potential gradient between the spine head and the parent dendrite could attract charged molecules (e.g., proteins) into the spine head where they might be used for synapse stabilization (Horwitz, 1984). Spine neck constriction may also enhance the biochemical specificity of synapses, by concentrating calcium, sccond messengers, protcascs, and other molecules in the spine heads near to the activated synapses (Gamble and Koch, 1987; Brown et al., 1988; Harris and Stevens, 1988, 1989; Wickens, 1988). The presence of binding proteins and a mature spine apparatus could further specify this molecular compartmentation in the spine heads (Cumming and Burgoyne, 1983; Fifkova, 1985). Together, these observations suggest that spine neck con- striction may amplify the potential generated in the spine head and enhance the biochemical specificity of the activated synapses, without reducing the transmission of an electrical signal to the parent dendrite or to neighboring dendritic spines.

Similarly, the dramatic shift in the predominance of thin and mushroom spines during maturation could alter the physiology of LTP. At PND7, a few synapses occur predominantly on dendritic shafts or stubby dendritic spines and LTP lasts for less than $2 \mathrm{hr}$ posttetanus (Harris and Teyler, 1984; Harris et al., 1987, 1989; Jackson et al., 1991). By PND15 about half of the spines and synapses are present, suggesting that a minimum number of spines and synapses may be required to produce an enduring potentiation. At neither PND15 nor adult ages are the spine necks likely to be thin or long enough to reduce charge transfer from the synapse to the parent dendrite; therefore, a shortening and widening of the spine necks is unlikely to mediate LTP at either age (see also Jung et al., 1991). Since most of the PND15 spines are stubby with wide necks, calcium, second messengers, or other molecules may readily diffuse into the dendrites and influence nonpotentiated synapses elsewhere on the dendrites. Such a nonspecific spread of potentiation could enhance the magnitude of LTP during the early posttetanus period at PND15 relative to adults, where constricted spine necks could reduce this nonspecific spread of potentiation. Diffusion of molecules away from potentiated synapses could reduce the concentration of I.TP-specific molecules that are required to stabilize whatever changes mediate enduring LTP. In contrast, the predominance of spines with constricted necks in the mature hippocampus may reduce diffusion of molecules, such as calcium (Muller and Connor, 1991), thereby enhancing the specificity and stability of mature LTP and accounting for the lower magnitude and greater endurance of LTP in the mature hippocampal area CA1. Clearly, the age of the animal and the associated postsynaptic structure of dendritic spines needs to be considered to elucidate the relative contributions of pre- and postsynaptic mechanisms in LTP.

Considerable evidence has accumulated to suggest that changes in spine and synaptic structure accompany LTP (see Wallace et al., 1991, for review), yet controversy remains as to whether new spines and synapses form or the geometries of existing spines and synapses change. In hippocampal area dentata, early results from single section studies suggested that dendritic spines swell with LTP, possibly reducing the spine neck resistance and enhancing charge transfer to the postsynaptic dendrites (Van Harreveld and Fifkova, 1975; Fifkova and Van Harreveld, 1977). More recent findings in area dentata from single sections also suggest a change in the morphology of existing synapses but no change in the number of synapses with LTP (Desmond and Levy, 1986, 1988, 1990). In contrast, another study utilizing serial EM reconstructions of individual dendrites suggests a doubling in spine number along their length, more branched spines, and more spines with wide necks after LTP (Andersen et al., 1987a,b; Trommald et al., 1990). Low synaptic densities from single section analyses and a potentially high bias from serial reconstructions (if the dendrites with attached spines were selected for reconstruction) may account for some of the discrepancies between these studies. In area CAl, no significant changes in the overall density of spine synapses have been detected between hippocampus with and without LTP (Lee et al., 1980; Chang and Greenough, 1984). However, the single section approach utilized in these studies may not have detected many of the spine synapses (see above), and therefore could have missed 
changes in spine density with LTP. In the same studies, analysis of longitudinally sectioned spines determined that stubby spines increase in number after LTP, but no data exist on the fate of the predominant thin, mushroom, or branched spines with LTP in area CA1.

To discern whether a specific dendritic spine is remodeled would require monitoring all parts of its three-dimensional structure throughout life, which as yet is impossible, though improvements in confocal microscopy may facilitate this process (Keenan et al., 1990; Deitch et al., 1991; Fine et al., 1991; Turner et al., 1991). However, serial EM will still be required to measure changes in spine dimensions, PSD characteristics, and subcellular composition. Since these morphological characteristics distinguish spines in different categories, the possibility remains that the distinct spine categories have physiologically distinct functions. Application of the series sample method in combination with three-dimensional reconstructions should help to discern unequivocally whether physiological events such as LTP remodel existing dendritic spines and synapses and/or alter their number.

\section{References}

Andersen P (1987) Properties of hippocampal synapses of importance for integration and memory. In: Synaptic function (Edelman GM, Gall WE, Cowan WM, eds), pp 403-429. New York: Wiley.

Andersen P, Blackstad T, Hulleberg G, Trommald M, Vaaland JL (1987a) Dimensions of dendritic spines of rat dentate granule cells during long-term potentiation (LTP). J Physiol (Lond) 390:264.

Andersen P, Blackstad T, Hulleberg G, Vaaland JL, Trommald M (1987b) Changes in spine morphology associated with LTP in rat dentate granule cells. Proc Physiol Soc PC50:288P.

Andrews SB, Leapman RD, Landis DMD, Reese TS (1988) Activitydependent accumulation of calcium in Purkinje cell dendritic spines. Proc Natl Acad Sci USA 85:1682-1685.

Baer SM, Rinzel J (1991) Propagation of dendritic spikes mediated by excitable spines: a continuum theory. J Neurophysiol 65:874-890.

Baudry M, Davis JL (1991) Long-term potentiation: a debate of current issues. Cambridge, MA: MIT Press.

Baudry M, Arst D, Oliver M, Lynch G (1981) Development of glutamate binding sites and their regulation by calcium in rat hippocampus. Dev Brain Res 1:37-48.

Bekkers JM, Stevens CF (1990) Presynaptic mechanism for long-term potentiation in the hippocampus. Nature 346:724-729.

Bekkers JM, Richerson GB, Stevens CF (1990) Origin of variability in quantal size in cultured hippocampal neurons and hippocampal slices. Proc Natl Acad Sci USA 87:5359-5362.

Benshalom G (1989) Structural alterations of dendritic spines induced by neural degeneration of their presynaptic afferents. Synapse 4:210222.

Benshalom G, White EL (1988) Dendritic spines are susceptible to structural alterations induced by degeneration of their presynaptic afferents. Brain Res 443:377-382.

Blackstad TW, Kjaerheim A (1961) Special axo-dendritic synapses in the hippocampal cortex: electron and light microscopic studies in the layer of mossy fibers. J Comp Neurol 117:133-159.

Braendgaard H, Gundersen HJ (1986) The impact of recent stereological advances on quantitative studies of the nervous system. $J$ Neurosci Methods 18:39-78.

Brown TH, Chang VC, Ganong AH, Keenan CL, Kelso SR (1988) Biophysical properties of dendrites and spines that may control the induction and expression of long-term synaptic potentiation. In: Longterm potentiation: From biophysics to behavior. Neurology and neurobiology, Vol 35 (Landfield PW, Deadwyler SA, eds), pp. 201-264. New York: Liss.

Burgoyne RD, Gray EG, Barron J (1983) Cytochemical localization of calcium in the dendritic spine apparatus of the cerebral cortex and at synaptic sites in the cerebellar cortex. J Anat 136:634-635.

Carlin RK, Siekevitz P (1983) Plasticity in the central nervous system: do synapses divide? Proc Natl Acad Sci USA 80:3517-3521.

Chang FL, Greenough WT (1984) Transient and enduring morpho- logical correlates of synaptic activity and efficacy in the rat hippocampal slice. Brain Res 309:35-46.

Chicurel ME, Harris KM (1989) Serial electron microscopy of CA3 dendritic spines synapsing with mossy fibers of rat hippocampus. Soc Neurosci Abstr 15:256.

Coss RG, Perkel DH (1985) The function of dendritic spines-a review of theoretical issues. Behav Neurol Biol 44:151-185.

Cumming R, Burgoyne RD (1983) Compartmentalization of neuronal cytoskeletal proteins. Biosci Rep 3:997-1006.

Deitch JS, Smith KL, Swann JW, Turner JN (1991) Ultrastructural investigation of neurons identified and localized using the confocal scanning laser microscope. J Electron Microsc Technique 18:82-90.

Desmond NL, Levy WB (1986) Changes in the postsynaptic density with long-term potentiation in the dentate gyrus. J Comp Neurol 253: 476-482.

Desmond NL, Levy WB (1988) Synaptic interface surface area increases with long-term potentiation in the hippocampal dentate gyrus. Brain Res 453:308-314.

Desmond NL, Levy WB (1990) Morphological correlates of long-term potentiation imply the modification of existing synapses, not synaptogenesis, in the hippocampal dentate gyrus. Synapse 5:139-143.

Diamond J, Gray EG, Yasargil GM (1970) The function of the dendritic spine: an hypothesis. In: Excitatory synaptic mechanisms (Andersen P, Jensen JKS, eds), pp 213-222. Oslo: Universitetsforlaget.

Feldman ML, Peters A (1979) A technique for estimating total spine numbers on Colgi-impregnated dendrites. I Comp Neurol 188:527542.

Fifkova E (1985) Actin in the nervous-system. Brain Res Rev 9:187215.

Fifkova E, Van Harreveld A (1977) Long-lasting morphological changes in dendritic spines of dentate granular cells following stimulation of the entorhinal area. J Neurocytol 6:211-230.

Fifkova E, Markham JA, Delay RJ (1983) Calcium in the spine apparatus of dendritic spines in the dentate molecular layer. Brain Res 266:163-168.

Fine A, Hosakawa T, Bliss TVP (1991) Confocal imaging of changes in synaptic structure in living hippocampal slices. Soc Neurosci Abstr 17:1328.

Foster TC, McNaughton BL (1991) Long term enhancement of CA1 synaptic transmission is due to an increase in quantal size, not quantal content. Hippocampus 1:79-91.

Friedlander MJ, Sayer RJ, Redman SJ (1990) Evaluation of long-term potentiation of small compounds and unitary EPSPs at the hippocampal CA3-CA1 synapse. J Neurosci 10:814-825.

Gamble E, Koch C (1987) The dynamics of free calcium in dendritic spines in response to repetitive synaptic input. Science 236:13111315.

Geinisman Y, de Toledo-Morrell L, Morrell F (1986) Aged rats need a preserved complement of perforated axospinous synapses per hippocampal neuron to maintain good spatial memory. Brain Res 398 : 266-275.

Geinisman Y, Morrell F, de Toledo-Morrell L (1989) Perforated synapses on double-headed dendritic spines: a possible structural substrate of synaptic plasticity. Brain Res 480:326-329.

Gray EG (1959) Axosomatic and axodendritic synapses of the cerebral cortex: an electron microscopic study. J Anat 83:420-433.

Greenough WT, Bailey CH (1988) The anatomy of a memory: convergence of results across a diversity of tests. Trends Neurosci 11 : 142-147.

Hamlyn LH (1962) The fine structure of the mossy fibre endings in the hippocampus of the rabbit. J Anat 96:112-120.

Harris KM, Landis DMD (1986) Membrane structure at synaptic junctions in area CA1 of the rat hippocampus. Neuroscience 19:857872.

Harris KM, Stevens JK (1988a) Dendritic spines of rat cerebellar Purkinje cells: serial electron microscopy with reference to their biophysical characteristics. J Neurosci 8:4455-4469.

Harris KM, Stevens JK (1988b) Study of dendritic spines by serial electron microscopy and three-dimensional reconstructions. In: Intrinsic determinants of neuronal form and function. Neurology and neurobiology, vol 37 (Lasek RJ, Black MM, eds) pp 179-199. New York: Liss.

Harris KM, Stevens IK (1989) Dendritic spines of CA1 pyramidal cells in the rat hippocampus: serial electron microscopy with reference to their biophysical characteristics. J Neurosci 9:2982-2997. 
Harris KM, Teyler TJ (1983) Evidence for late development of inhibition in area CAl of the rat hippocampus. Brain Res 268:339343.

Harris KM, Teyler TJ (1984) Developmental onset of long-term potentiation in area CAl of the rat hippocampus. J Physiol (Lond) 346: $27-48$.

Harris KM, Jensen FE, Tsao B (1987) Development of hippocampal synapses, spines, and LTP. Soc Neurosci Abstr 13:1429.

Harris KM, Jensen FE, Tsao B (1989) Ultrastructure, development, and plasticity of dendritic spine synapses in area CAl of the rat hippocampus: Extending our vision with serial electron microscopy and three-dimensional analyses. In: The hippocampus-new vistas, neurology and neurobiology, vol 52 (Chan-Palay V, Kohler C, eds), pp 33-52. New York: Liss.

Horwitz B (1984) Electrophoretic migration due to postsynaptic potential gradients: theory and application to autonomic ganglion neurons and to dendritic spines. Neuroscience 12:887-905.

Jackson PS, Suppes T, Harris KM (1991) Dramatic differences in the magnitude and temporal development of long-term potentiation (LTP) in rat hippocampal area CAl at postnatal days 11 and 15 . Soc Neurosci Abstr 17:386.

Jones EG, Powell TPS (1969) Morphological variations in the dendritic spines of the neocortex. J Cell Sci 5:509-529.

Jung MW, Larson J, Lynch G (1991) Evidence that changes in spine neck resistance are not responsible for expression of LTP. Synapse 7: 216-220.

Kawato M, Tsukahara N (1983) Theoretical study on electrical properties of dendritic spines. J Theor Biol 103:507-522.

Keenan CL, Nobre AC, Claiborne BJ, Brown TH (1990) Visualization of living hippocampal synapses using confocal scanning laser microscopy. Soc Neurosci Abstr 16:660.

Koch C, Poggio T (1983) Electrical properties of dendritic spines. Trends Neurosci 6:80-83.

Lee KS, Schottler F, Oliver M, Lynch G (1980) Brief bursts of highfrequency stimulation produce two types of structural change in the rat hippocampus. J Neurophysiol 44:247-258.

Malenka RC (1991) Postsynaptic factors control the duration of synaptic enhancement in area CAl of the hippocampus. Neuron 6:5360 .

Malinow R, Tsien RW (1990) Presynaptic enhancement shown by whole-cell recordings of long-term potentiation in hippocampal slices. Nature 346:175-180.

McNaughton BL (1991) The mechanisms of expression of long-term synaptic enhancement: thesis, antithesis, synthesis. In: Long-term potentiation: a debate of current issues (Baudry M, Davis JL, eds), pp 77-92. Cambridgc, MA: MIT Press.

Michelson HB, Lothman EW (1989) An in vivo electrophysiological study of the ontogeny of excitatory and inhibitory processes in the rat hippocampus. Dev Brain Res 46:113-122.

Mignery GA, Sudhof TC, Takei K, DeCamilli P (1989) Putative receptor for inositol 1,4,5-trisphosphate similar to ryanodine receptor. Nature 342:192-195.

Miller JP, Rall W, Rinzel J (1985) Synaptic amplification by active membrane in dendritic spines. Brain Res 325:325-330.

Minkwitz HG (1976) Zur Entwicklung der Neuronenstruktur des Hippocampus wahrend der pra- und postnatalen Ontogenese der Albinoratte. III. Mitteilung: Morphometrische Erfassung der ontogenetischen Veranderungen in Dendritenstruktur und Spinebesatz an Pyramidenneuronen (CAl) des Hippocampus. J Hirnforsch 17:255275.

Muller D, Oliver M, Lynch G (1989) Developmental changes in synaptic properties in hippocampus of neonatal rats. Dev Brain Res 49: 105-114.

Muller W, Connor JA (1991) Dendritic spines as individual neuronal compartments for synaptic $\mathrm{Ca}^{2+}$ responses. Nature 354:73-76.

Nieto-Sampedro M, Hoff SF, Cotman CW (1982) Perforated postsynaptic densities: probable intermediates in synapse turnover. Proc Natl Acad Sci USA 79:5718-5722.

Pearlstein RA, Kirschner L, Simons J, Machell S, White WF, Sidman RL (1986) A multimodal system for reconstruction and quantification of neurologic structures. Anal Quant Cytol Histol 8:108-115.

Perkel DH, Perkel DJ (1985) Dendritic spines: role of active membrane in modulating synaptic efficacy. Brain Res 325:331-335.

Peters A, Kaiserman-Abramof IR (1970) The small pyramidal neuron of the rat cerebral cortex. The perikaryon, dendrites and spines. J Anat 127:321-356.
Pokorny J, Yamamoto T (1981) Postnatal ontogenesis of hippocampal $\mathrm{CAl}$ area in rats. II. Development of ultrastructure in stratum lacunosum and moleculare. Brain Res Bull 7:121-130.

Purpura DP (1974) Dendritic spine "dysgenesis" and mental retardation. Science 186:1126-1128.

Purpura DP (1975) Dendritic differentiation in human cerebral cortex: normal and aberrant developmental patterns. In: Physiology and pathology of dendrites (Kretzberg GW, ed), pp 91-116. New York: Raven.

Purpura DP, Prelevic S, Santini M (1968) Postsynaptic potentials and spike variations in the feline hippocampus during postnatal ontogenesis. Exp Neurol 22:408-422.

Rall W (1970) Cable properties of dendrites and effects of synaptic location. In: Excitatory synaptic mechanisms (Andersen P, Jensen JKS, eds), pp 175-187. Oslo: Universitetsforlaget.

Rall W (1974) Dendritic spines, synaptic potency, and neuronal plasticity. In: Cellular mechanisms subserving changes in neuronal activity (Woody C, Brown K, Crow T, Knispel J, eds), pp 13-21. Los Angeles: Brain Information Service.

Rall W (1977) Core conductor theory and cable properties of neurons. In: Handbook of physiology - the nervous system (Kandel ER, ed), pp 39-97. Bethesda, MD: American Physiological Society.

Rall W (1978) Dendritic spines and synaptic potency. In: Studies in neurophysiology (McIntyre AK, Porter K, eds), pp 203-209. Cambridge: Cambridge UP.

Ramon y Cajal S (1893) Neue Darstellung vom Histologischen Bau des Centrainervensystems. Archiv fur Anatomie und Entwickelungsgeschichte. Anatomische Abtheilung des Archives fur Anatome und Physiologie 319-428.

Scheibel ME, Scheibel AB (1968) On the nature of dendritic spines: report of a workshop. Commun Behav Biol Al:231-265.

Schuz A (1978) Some facts and hypotheses concerning dendritic spines and learning. In: Architectonics of the cerebral cortex (Brazier MAB, Petsche H, eds), pp 129-135. New York: Raven.

Schwartzkroin PA (1982) Development of rabbit hippocampus: physiology. Dev Brain Res 2:469-486.

Schwartzkroin PA, Altschuler RJ (1977) Development of kitten hippocampal neurons. Brain Res 134:429-444.

Schwartzkroin PA, Kunkel DD, Mathers L (1982) Development of rabbit hippocampus: anatomy. Dev Brain Res 2:453-468.

Segev I, Rall W (1988) Computational study of an excitable dendritic spine. J Neurophysiol 60:499-523.

Shepherd GM, Brayton RK, Miller JP, Segev I, Rinzel J, Rall W (1985) Signal enhancement in distal cortical dendrites by means of interactions between active dendritic spines. Proc Natl Acad Sci USA 82: 2192-2195.

Spacek J (1980) Non-synaptic membrane specializations on the necks of Purkinje cell dendritic spines. J Anat 131:723-729.

Spacek J (1985a) Three-dimensional analysis of dendritic spines. II. Spine apparatus and other cytoplasmic components. Anat Embryol 171:235-243.

Spacek J (1985b) Relationships between synaptic junctions, puncta adhaerentia and the spine apparatus at neocortical axo-spinous synapses. Anat Embryol 173:129-135.

Spacek J, Hartmann M (1983) Three-dimensional analysis of dendritic spines: I. Quantitative observations related to dendritic spine and synaptic morphology in cerebral and cerebellar cortices. Anat Embryol 167:289-310.

Stevens JK, Trogadis J (1984) Computer assisted reconstruction from serial electron micrographs. Annu Rev Neurobiul 5:341-369.

Stevens JK, Davis T, Friedman N, Sterling P (1980) A systematic approach to reconstructing microcircuitry by electron microscopy of serial sections. Brain Kes Kev 2:265-293.

Tanzi E (1893) I Fatti i le induzioni nell'odierna istologia del sistema nervoso. Riv Sper Freniatr Med Leg Alienazioni Ment 19:419-472.

Trommald M, Vaaland JL, Blackstad TW, Andersen P (1990) Dendritic spine changes in rat dentate granule cells associated with longterm potentiation. In: Neurotoxicity of excitatory amino acids (Guidotti A, ed), pp 163-174. New York: Raven.

Turner DA (1988) Waveform and amplitude characteristics of evoked responses to dendritic stimulation of $\mathrm{CA} 1$ guinea-pig pyramidal cells. J Physiol (Lond) 395:419-439.

Turner JN, Szarowski DH, Smith KL, Marko M, Leith A, Swann JW (1991) Confocal microscopy and three-dimensional reconstruction of electrophysiologically identified neurons in thick brain slices. $J$ Electron Microsc Technique 18:11-23. 
Van Harreveld A, Fifkova E (1975) Swelling of dendritic spines in the fascia dentata after stimulation of the perforant fibers as a mechanism of post-tetanic potentiation. Exp Neurol 49:736-749.

Wallace C, Hawrylak N, Greenough WT (1991) Studies of synaptic structural modifications after long-term potentiation and kindling: context for a molecular morphology. In: Long-term potentiation: a debate of current issues (Baudry M, Davis JL, eds), pp 189-232. Cambridge, MA: MIT Press.

Westrum LE, Blackstad T (1962) An electron microscopic study of the stratum radiatum of the rat hippocampus (regio superior, CA1) with particular emphasis on synaptology. J Comp Neurol 119:281309.
Westrum LE, Jones DH, Gray EG, Barron J (1980) Microtubules, dendritic spines and spine apparatuses. Cell Tissue Res 208:171-181.

Wickens J (1988) Electrically coupled but chemically isolated synapses: dendritic spines and calcium in a rule for synaptic modification. Prog Neurobiol 31:507-528.

Wilson CJ (1984) Passive cable properties of dendritic spines and spiny neurons. J Neurosci 4:281-297.

Wilson CJ, Groves PM, Kitai ST, Linder JC (1983) Three dimensional structure of dendritic spines in rat striatum. J Neurosci 3:383-398.

Woolf TB, Shepherd GM, Greer CA (1991) Local information processing in dendritic trees: subsets of spines in granule cells of the mammalian olfactory bulb. J Neurosci 11:1837-1854. 